\title{
Amplification of black carbon light absorption induced by atmospheric aging: temporal variation at seasonal and diel scales in urban Guangzhou
}

\author{
Jia Yin Sun ${ }^{1,2}$, Cheng Wu ${ }^{1,2}$, Dui Wu ${ }^{1,2,3}$, Chunlei Cheng ${ }^{1,2}$, Mei Li ${ }^{1,2}$, Lei Li ${ }^{1,2}$, Tao Deng ${ }^{3}$, Jian Zhen Yu ${ }^{4,5,6}$, \\ Yong Jie Li ${ }^{7}$, Qianni Zhou ${ }^{1,2}$, Yue Liang ${ }^{1,2}$, Tianlin Sun ${ }^{1,2}$, Lang Song ${ }^{1,2}$, Peng Cheng ${ }^{1,2}$, Wenda Yang ${ }^{1,2}$, \\ Chenglei Pei ${ }^{8,9,10}$, Yanning Chen ${ }^{10}$, Yanxiang Cen ${ }^{11}$, Huiqing Nian ${ }^{11}$, and Zhen Zhou ${ }^{1,2}$ \\ ${ }^{1}$ Institute of Mass Spectrometry and Atmospheric Environment, Jinan University, Guangzhou 510632, China \\ ${ }^{2}$ Guangdong Provincial Engineering Research Center for Online Source Apportionment System of Air Pollution, \\ Guangzhou 510632, China \\ ${ }^{3}$ Institute of Tropical and Marine Meteorology, CMA, Guangzhou 510080, China \\ ${ }^{4}$ Department of Chemistry, Hong Kong University of Science and Technology, Hong Kong, China \\ ${ }^{5}$ Division of Environment and Sustainability, Hong Kong University of Science and Technology, Hong Kong, China \\ ${ }^{6}$ Atmospheric Research Center, HKUST Fok Ying Tung Research Institute, Guangzhou 511400, China \\ ${ }^{7}$ Faculty of Science and Technology, University of Macau, Macau, China \\ ${ }^{8}$ State Key Laboratory of Organic Geochemistry and Guangdong Key Laboratory of Environmental Protection and Resources \\ Utilization, Guangzhou Institute of Geochemistry, Chinese Academy of Sciences, Guangzhou 510640, China \\ ${ }^{9}$ University of Chinese Academy of Sciences, Beijing 100049, China \\ ${ }^{10}$ Guangzhou Environmental Monitoring Center, Guangzhou 510030, China \\ ${ }^{11}$ Guangzhou Hexin Analytical Instrument Company Limited, Guangzhou 510530, China
}

Correspondence: Cheng Wu (wucheng.vip@foxmail.com), Dui Wu (wudui.vip@foxmail.com), and Zhen Zhou (zhouzhen@gig.ac.cn)

Received: 17 July 2019 - Discussion started: 4 November 2019

Revised: 11 January 2020 - Accepted: 27 January 2020 - Published: 28 February 2020

\begin{abstract}
Black carbon (BC) aerosols have been widely recognized as a vital climate forcer in the atmosphere. Amplification of light absorption can occur due to coatings on BC during atmospheric aging, an effect that remains uncertain in accessing the radiative forcing of BC. Existing studies on the absorption enhancement factor $\left(E_{\mathrm{abs}}\right)$ have poor coverage on both seasonal and diurnal scales. In this study, we applied a recently developed minimum $R$ squared (MRS) method, which can cover both seasonal and diurnal scales, for $E_{\text {abs }}$ quantification. Using field measurement data in Guangzhou, the aims of this study are to explore (1) the temporal dynamics of BC optical properties at seasonal (wet season, 31 July-10 September; dry season, 15 November 201715 January 2018) and diel scales (1 h time resolution) in the typical urban environment and (2) the influencing factors on $E_{\text {abs }}$ temporal variability. Mass absorption efficiency
\end{abstract}

at $520 \mathrm{~nm}$ by primary aerosols $\left(\mathrm{MAE}_{\mathrm{p} 520}\right)$ determined by the MRS method exhibited a strong seasonality $\left(8.6 \mathrm{~m}^{2} \mathrm{~g}^{-1}\right.$ in the wet season and $16.8 \mathrm{~m}^{2} \mathrm{~g}^{-1}$ in the dry season). $E_{\text {abs520 }}$ was higher in the wet season $(1.51 \pm 0.50)$ and lower in the dry season $(1.29 \pm 0.28)$. Absorption Ångström exponent $\left(\mathrm{AAE}_{470-660}\right)$ in the dry season $(1.46 \pm 0.12)$ was higher than that in the wet season $(1.37 \pm 0.10)$. Collective evidence showed that the active biomass burning (BB) in the dry season effectively altered the optical properties of $\mathrm{BC}$, leading to elevated MAE, MAE $\mathrm{p}$ and AAE in the dry season compared to those in the wet season. Diurnal $E_{\text {abs520 }}$ was positively correlated with $\mathrm{AAE}_{470-660}\left(R^{2}=0.71\right)$ and negatively correlated with the AE33 aerosol loading compensation parameter $(k)\left(R^{2}=0.74\right)$ in the wet season, but these correlations were significantly weaker in the dry season, which may be related to the impact of $\mathrm{BB}$. This result suggests that during 
the wet season, the lensing effect was more likely dominating the AAE diurnal variability rather than the contribution from brown carbon $(\mathrm{BrC})$. Secondary processing can affect $E_{\text {abs }}$ diurnal dynamics. The $E_{\text {abs520 }}$ exhibited a clear dependency on the ratio of secondary organic carbon to organic carbon (SOC/OC), confirming the contribution of secondary organic aerosols to $E_{\text {abs }} ; E_{\text {abs520 }}$ correlated well with nitrate and showed a clear dependence on temperature. This new finding implies that gas-particle partitioning of semivolatile compounds may potentially play an important role in steering the diurnal fluctuation of $E_{\text {abs520. }}$. In the dry season, the diurnal variability in $E_{\text {abs } 520}$ was associated with photochemical aging as evidenced by the good correlation $\left(R^{2}=0.69\right)$ between oxidant concentrations $\left(\mathrm{O}_{x}=\mathrm{O}_{3}+\mathrm{NO}_{2}\right)$ and $E_{\text {abs520. }}$.

\section{Introduction}

Atmospheric aerosols have received great attention in recent years due to their global climatic effects and environmental effects (Anderson et al., 2003). Carbonaceous aerosols account for a large fraction of the global aerosol mass as the main light-absorbing materials in aerosols (Kanakidou et al., 2005; Bond and Bergstrom, 2006). Black carbon (BC), which originates from incomplete combustion of hydrocarbon fuels (Johansson et al., 2018), is the dominating fraction of light-absorbing carbonaceous aerosols. BC has been widely recognized not only as an air pollutant that poses a threat to public health (Grahame et al., 2014; Apte et al., 2015) but also as an essential climate forcer (Chung and Seinfeld, 2002). The BC burden in the atmosphere increased substantially in recent years as evidenced by the ice core samples (Ruppel et al., 2014) and sediment cores from the eastern China marginal seas (Fang et al., 2018). The growing abundance of $\mathrm{BC}$ in the atmosphere leads to elevated environmental impacts. $\mathrm{BC}$ has been regarded as the third most important climate forcer after carbon dioxide and methane (IPCC, 2013). On a global scale, BC can heat the atmospheric directly owing to its strong light absorption across the solar spectrum (Bond and Bergstrom, 2006), thus contributing to the warming effect (Bond et al., 2013). On a regional scale, $\mathrm{BC}$ deposition on ice and snow can reduce surface albedo, leading to glacier melting (Gertler et al., 2016; Kopacz et al., 2011; Flanner et al., 2007; He et al., 2018; Hansen and Nazarenko, 2004), especially at high-altitude regions such as the Tibetan Plateau (Ming et al., 2008). On a local scale, BC can modify planetary boundary layer meteorology that leads to the "dome effect", and thus enhances local pollution indirectly (Ding et al., 2016; Wilcox et al., 2016). At the microscale, BC was found to play a key role in the photochemical aging of soot by initiating the oxidation of OC (M. Li et al., 2018). In addition, BC can indirectly affect the climate by altering cloud formation and cloud cover
(Nenes et al., 2002; Koch and Del Genio, 2010; Kaufman and Koren, 2006; Albrecht, 1989).

However, large uncertainties still exist in estimating the radiative forcing of BC (Bond et al., 2013). The gap largely arises from the limited characterization of $\mathrm{BC}$ mixing state and optical properties in the atmosphere (Fuller et al., 1999; Jacobson, 2001; Nordmann et al., 2014). BC is chemically inert, but morphology transformation is unavoidable once emitted into the atmosphere. A recent study suggested that $\mathrm{BC}$ restructuring during aging can be divided into two steps (Pei et al., 2018). First, the void of the BC particles will be filled by the aging-induced materials. Once filled, further accumulation of organic and inorganic coating materials leads to the growth of particle size. Ma et al. (2013) reported soot restructuring during water evaporation in a laboratory study. Such morphology transformation leads to alternation of BC optical properties, as evidenced by a number of numerical studies (Fuller et al., 1999; Bond et al., 2006; F. Liu et al., 2016; Zhang et al., 2017; Lefevre et al., 2019), laboratory experiments (Schnaiter et al., 2005; Zhang et al., 2008; Xue et al., 2009; Shiraiwa et al., 2010; Metcalf et al., 2013; Wei et al., 2013; Chen et al., 2015) and field studies (Knox et al., 2009; Cappa et al., 2012; Lack et al., 2012b; Liu et al., 2015, 2019b; D. Liu et al., 2017). The presence of coating materials on BC leads to the increase in mass absorption efficiency (MAE) through the lensing effect (Schwarz et al., 2008b). Besides coating thickness, the magnitude of light absorption enhancement by the lensing effect also depends on the optical properties of the coating materials. A coating of brown carbon $(\mathrm{BrC})$ can further amplify the light absorption compared to a transparent coatings (Lack and Cappa, 2010). Recent studies suggested that BC mixing state diversity also affects the bulk $E_{\text {abs }}$ (Fierce et al., 2016; Matsui et al., 2018; Cappa et al., 2019).

The total BC light absorption ( $\left.\sigma_{\text {abs_total }}\right)$ after aging can be segregated into primary absorption $\left(\sigma_{\text {abs_pri }}\right)$ by the $\mathrm{BC}$ core and the additional absorption ( $\sigma_{\text {abs_aging }}$ ) due to the presence of a coating:

$\sigma_{\text {abs_total }}=\sigma_{\text {abs_pri }}+\sigma_{\text {abs_aging }}$.

The key parameter for light absorption enhancement, $E_{\mathrm{abs}}$, can be calculated from

$E_{\text {abs }}=\frac{\sigma_{\text {abs_total }}}{\sigma_{\text {abs_pri }}}=\frac{\mathrm{MAE}_{\mathrm{t}}}{\mathrm{MAE}_{\mathrm{p}}}$,

where $\mathrm{MAE}_{\mathrm{t}}$ is the MAE of coated BC,

$\mathrm{MAE}_{\mathrm{t}}=\frac{\sigma_{\text {abs_total }}}{\mathrm{EC}}$,

and $\mathrm{MAE}_{\mathrm{p}}$ represents the MAE of BC when fleshly emitted,

$\mathrm{MAE}_{\mathrm{p}}=\frac{\sigma_{\text {abs_pri }}}{\mathrm{EC}}$.

EC in Eqs. (3) and (4) represents elemental carbon (EC) mass concentration determined by the thermo-optical analysis method (Wu et al., 2012), which can be considered a 
surrogate of $\mathrm{BC}$ mass concentration. The atmospheric aging process can lead to $\mathrm{BC} E_{\mathrm{abs}}$ values larger than 1 due to the increase in $\mathrm{MAE}_{\mathrm{t}}$.

Three technical approaches have been applied for $E_{\text {abs }}$ quantification as summarized in Table 1. The first approach is to use a thermal denuder (TD) upstream of the instrument that measures $\sigma_{\text {abs }}$ (e.g., PAS, photoacoustic spectrometer). By measuring the denuded and ambient sample in rotation with a desired interval (e.g., $5 \mathrm{~min}$ ), $\sigma_{\text {abs_total }}$ and $\sigma_{\text {abs_pri }}$ can be obtained to determine $E_{\text {abs }}$ following Eq. (2). Particle loss in the TD is unavoidable and needs to be accounted for (Burtscher et al., 2001). The advantage of the TD is its ability to obtain high-time-resolution data (Cappa et al., 2012; Lack et al., 2012b; Liu et al., 2015; D. Liu et al., 2017). But the TD has its limitations. First, the TD is not suitable for longterm measurements (e.g., most studies last for a few weeks as shown in Table 2). Second, the selection of working temperature depends on the sample and varies by sampling site, which can largely affect the $E_{\text {abs }}$ measurement results. As a result, a universal optimal TD working temperature does not exist. If the temperature is too low, the coating materials cannot be fully vaporized. The study by Ma et al. (2020) showed that coating materials still account for $60 \%$ of particle mass after thermally denuding at a temperature of $280^{\circ} \mathrm{C}$, implying the incomplete removal of coating materials. On the other hand, if the temperature is too high, pyrolysis would occur (Irwin et al., 2013), leading to a biased $E_{\text {abs }}$ measurement. For example, G.-L. Li et al. (2018) explore the variability of TD temperature on $E_{\text {abs }}$ determination in Hong Kong. For a TD temperature of 50 to $200^{\circ} \mathrm{C}, E_{\mathrm{abs}}$ ranges from 1.02 to 1.20 . $E_{\mathrm{abs}}$ reaches 1.6 for a TD temperature of $280^{\circ} \mathrm{C}$. Third, the TD approach cannot perfectly reverse the morphology transformation of $\mathrm{BC}$ from the aged state back to the freshly emitted state. Previous studies have shown that the chain-like aggregate morphology of nascent BC cannot be restored after thermally denuding the coatings on the reconstructed BC core, which tends to be more compact and spherical (Bambha et al., 2013; Ghazi and Olfert, 2013). In addition, the high cost of a TD-PAS system thwarts its wider applications in field studies.

The second approach for $E_{\text {abs }}$ determination is aerosol filter filtration-dissolution (AFD). AFD removes coatings on BC using water and organic solvents (X. Cui et al., 2016). The advantage of AFD is that this method can be applied on historical filters archived by long-term large-scale speciation sampling networks. It opens up a new path to retrieve the historical $E_{\text {abs }}$ from datasets with large temporal and spatial coverage. The limitation mainly arises from the AFD treatment process, which only removes the soluble part of the coating. The AFD treatment process is also labor intensive. The time resolution of $E_{\mathrm{abs}}$ by AFD depends on the interval of filter sampling, which has a typical sampling time of $24 \mathrm{~h}$, making it difficult to study the diurnal pattern of $E_{\text {abs }}$.

The third approach is the MAE method. $E_{\text {abs }}$ is quantified from the ratio of $\mathrm{MAE}_{\mathrm{t}}$ to $\mathrm{MAE}_{\mathrm{p}}$ as shown in Eq. (2). Since
$\mathrm{MAE}_{\mathrm{t}}$ can be obtained from ambient measurements, the determination of $\mathrm{MAE}_{\mathrm{p}}$ is the key to this approach. One way is to adopt empirical MAE $\mathrm{F}_{\mathrm{p}}$ in the literature (F. Cui et al., 2016) (abbreviated as MAE + empirical hereafter). Since the realworld $\mathrm{MAE}_{\mathrm{p}}$ could be highly diverse by different sources and varies temporally and spatially (Roden et al., 2006; Adler et al., 2010; Shen et al., 2013; McMeeking et al., 2014; Healy et al., 2015; Cheng et al., 2016; Weyant et al., 2016; Dastanpour et al., 2017; Radney et al., 2017; Conrad and Johnson, 2019), an empirical $\mathrm{MAE}_{\mathrm{p}}$ at one site might not be applicable at other sites.

Another method to determine $\mathrm{MAE}_{\mathrm{p}}$ is to combine $\sigma_{\text {abs_total }}$ measurements with single-particle measurements to provide the mixing state of BC, e.g., single-particle soot photometer (SP2) or soot particle aerosol mass spectrometer (SP-AMS). This method is abbreviated as MAE + SP hereafter for easy reference. The lag time between the incandescent signal and scattering in SP2 can be used to differentiate thickly coated BC and bare BC. The intercept of the linear regression between MAE ( $y$ axis) against the number fraction of aged BC ( $r_{\text {aged }}, x$ axis) represents $\mathrm{MAE}_{\mathrm{p}}$ (Lan et al., 2013; Wang et al., 2014). This method only considers $E_{\text {abs }}$ dependency on the number fraction of aged particles and ignores the coating thickness of the aged particles; thus, it is only valid for a limited period when coating thickness and size distribution are relatively stable. An improved method for $\mathrm{MAE}_{\mathrm{p}}$ determination by SP2 is utilizing the $\mathrm{rBC}$ size distribution to calculate the $\mathrm{MAE}_{\mathrm{p}}$ by the Mie model (D. Liu et al., 2017; Wang et al., 2018a, b).

A recently developed approach, the minimum $R$ squared method (MRS), can be applied to $\mathrm{MAE}_{\mathrm{p}}$ determination using elemental carbon as a tracer (Wu et al., 2018). MRS is a statistical approach, and $\mathrm{MAE}_{\mathrm{p}}$ can be determined in a quantitative manner that minimizes the arbitrariness in $\mathrm{MAE}_{\mathrm{p}}$ estimation by the traditional approach. Application of MRS for $E_{\text {abs }}$ determination is abbreviated as MAE + MRS for easy reference. As summarized in Table 1, the TD approach has high time resolution but limited sampling duration, while the AFD approach has a long sampling duration but low time resolution. As a result, studies of $E_{\text {abs }}$ with both high time resolution and long sampling duration are limited, leading to a lack of knowledge on $E_{\text {abs }}$ variability on both seasonal and diel scales. To fill this knowledge gap, the aims of this study are (1) to explore the temporal dynamics of $E_{\mathrm{abs}}$ on both seasonal and diel scales using the recently developed MRS approach and (2) to investigate the influencing factors on $E_{\text {abs }}$ temporal variability, including photochemical aging, biomass burning (BB) and BC mixing state. In this study, field measurements with $1 \mathrm{~h}$ time resolution were conducted in urban Guangzhou, a typical megacity in southern China in both wet (31 July-10 September 2017) and dry (15 November 2017-15 January 2018) seasons. Abbreviations used in this paper are listed in Table A1 in Appendix A for easy reference. 
Table 1. Comparisons of three $E_{\mathrm{abs}}$ determination approaches.

\begin{tabular}{|c|c|c|c|c|c|c|c|}
\hline \multicolumn{2}{|c|}{ Approach } & $\begin{array}{l}\text { Time } \\
\text { resolution }\end{array}$ & $\begin{array}{l}\text { Temporal } \\
\text { coverage }\end{array}$ & $\begin{array}{l}E_{\mathrm{abs}} \\
\text { determination }\end{array}$ & Instruments & Advantages & Limitations \\
\hline \multicolumn{2}{|c|}{ TD } & minutes & weeks & $E_{\text {abs }}=\frac{\sigma_{\text {abs_total }}}{\sigma_{\text {abs_pri }}}$ & $\mathrm{TD}+\mathrm{PAS}$ & $\begin{array}{l}\text { very high time } \\
\text { resolution }\end{array}$ & $\begin{array}{l}\text { TD temperature selection is } \\
\text { tricky; denuded particle mor- } \\
\text { phology different from emis- } \\
\text { sion }\end{array}$ \\
\hline \multicolumn{2}{|c|}{ AFD } & daily & years & & $\begin{array}{l}\text { filter sampler }+ \\
\text { offline OC/EC } \\
\text { analyzer }\end{array}$ & $\begin{array}{l}\text { can be applied } \\
\text { on archived fil- } \\
\text { ter samples }\end{array}$ & $\begin{array}{l}\text { labor intensive; only remove } \\
\text { soluble coating; low time res- } \\
\text { olution }\end{array}$ \\
\hline \multirow[t]{3}{*}{ MAE } & $\begin{array}{l}\mathrm{MAE}+ \\
\mathrm{MRS}\end{array}$ & hourly & years & $E_{\mathrm{abs}}=\frac{\mathrm{MAE}_{\mathrm{t}}}{\mathrm{MAE}_{\mathrm{p}}}$ & $\begin{array}{l}\text { Aeth }+ \text { online } \\
\text { OC/EC analyzer }\end{array}$ & $\begin{array}{l}\text { high time reso- } \\
\text { lution }\end{array}$ & $\begin{array}{l}\text { MRS has minimum data points } \\
\text { requirement, not suitable for a } \\
\text { small dataset }\end{array}$ \\
\hline & $\begin{array}{l}\text { MAE + } \\
\text { empirical }\end{array}$ & hourly & months & & $\begin{array}{l}\text { Aeth }+ \text { online } \\
\text { OC/EC analyzer }\end{array}$ & & $\begin{array}{l}\text { empirical } \mathrm{MAE}_{\mathrm{p}} \text { could be un- } \\
\text { realistic for the sampling site }\end{array}$ \\
\hline & $\begin{array}{l}\text { MAE + } \\
\text { SP }\end{array}$ & hourly & weeks & & $\begin{array}{l}\text { PAS/Aeth }+ \\
\text { SP2/SP-AMS }\end{array}$ & & $\begin{array}{l}\text { expensive instruments; } \\
\text { limited sampling duration }\end{array}$ \\
\hline
\end{tabular}

\section{Field measurements and data analysis methods}

\subsection{Characteristics of the observation site}

As shown in Fig. 1, sampling for this study was conducted at Jinan University (JNU) atmospheric supersite $\left(23.13^{\circ} \mathrm{N}\right.$, $113.35^{\circ} \mathrm{E} ; 40 \mathrm{~m}$ above sea level), which is located in Tianhe District, downtown Guangzhou. The site is on top of the library building and surrounded by teaching and residential areas. The campus is surrounded by the three busiest roads of the city (Fig. S1 in the Supplement), and traffic emissions are a major source of primary emissions. Guangzhou is located in southern China and is also the geographical center of Guangdong Province. There are limited industrial pollution sources around the sampling site, and thus this site can represent the typical urban environment in the Pearl River Delta (PRD) region.

The subtropical climate of the PRD is strongly affected by two monsoon systems: South China Sea (SCS) monsoon and northeast monsoon. April to May is the transition period for the northeast monsoon to the SCS monsoon. June to September is the SCS-monsoon-dominated period (wet season). The southern prevailing wind brings clean and humid air masses from the vast ocean. October is the transition period for the SCS monsoon to the northeast monsoon. November to March is the northeast-monsoon-dominated period (dry season). The northeastern prevailing wind brings polluted air masses from the more economically developed regions in eastern Asia. This study included two sampling periods: 31 July-10 September 2017 and 15 November 20177 January 2018, corresponding to the wet and dry seasons, respectively.

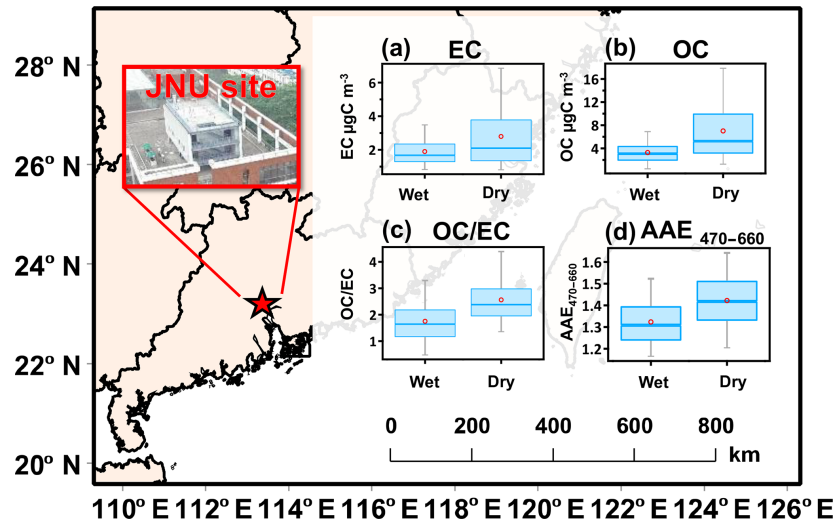

Figure 1. The location of the observation site (JNU). Panels (a), (b), (c) and (d) show the box plots of EC, OC, OC/EC and AAE $470-660$ during wet (July-September) and dry (November-January) seasons, respectively. Red circles represent the seasonal average. The line inside the box indicates the median. Upper and lower boundaries of the box represent the 75th and the 25th percentiles; the whiskers above and below each box represent the 95 th and 5th percentiles.

\subsection{Light absorption measurements}

A dual-spot Aethalometer (model AE33, Magee Scientific, Berkeley, CA, USA) was used for $\sigma_{\text {abs_total }}$ determination. Aethalometer sampling was performed at a flow rate of $5 \mathrm{~L} \mathrm{~min}^{-1}$ with a $2.5 \mu \mathrm{m}$ cyclone inlet. A Nafion dryer was used to maintain the $\mathrm{RH}<40 \%$. The data logging time resolution is $1 \mathrm{~min}$. The $\mathrm{AE} 33$ reports results in the form of equivalent $\mathrm{BC}$ mass $(\mathrm{eBC})$, which can be used to back-calculate the $\sigma_{\text {abs_total. }}$ MAE values from the study by Drinovec et al. (2015) were adopted for the $\sigma_{\text {abs_total }}$ back-calculation from $\mathrm{eBC}$ at different wavelengths as shown in Table S1 
in the Supplement. A multiple scattering correction factor, $C_{\text {ref }}=3.29$, was used according to a recent study in this region (Qin et al., 2018). As a filter-based method, the deposition of light-absorbing particles on filters leads to the attenuation of the filter transmittance signal, which is proportional to the $\mathrm{BC}$ mass concentration. However, as the particle deposition layer gradually increases, the light was blocked at the upper particle layer before reaching the underlying particle layer, resulting in a well-known artifact: the loading effect. Since the lower-layer particles did not contribute to the light attenuation, the linear relationship between $\mathrm{BC}$ mass concentration and light attenuation signal is distorted.

The AE33 adopted the "dual spot" design to minimize the loading effect (Drinovec et al., 2015), which is an improvement on the traditional "single spot" correction (Virkkula et al., 2007). Sampling of the two spots was performed simultaneously. The correction can be implemented for each wavelength by the following two equations:

$$
\begin{aligned}
& \mathrm{eBC} 1_{\text {raw }}=\mathrm{eBC}_{\text {compensated }} \cdot(1-k \cdot \mathrm{ATN} 1), \\
& \mathrm{eBC} 2_{\text {raw }}=\mathrm{eBC}_{\text {compensated }} \cdot(1-k \cdot \mathrm{ATN} 2),
\end{aligned}
$$

where $\mathrm{eBC} 1_{\text {raw }}$ and $\mathrm{eBC} 2_{\text {raw }}$ are the uncorrected $\mathrm{eBC}$ mass determined by the two spots. $\mathrm{eBC}_{\text {compensated }}$ is the corrected eBC concentration to be determined. $k$ is the empirical compensation parameter. ATN1 and ATN2 are the light attenuations measured at the two spots. The flows of the two spots were maintained at a ratio of $2: 1$ to achieve a differential increase in ATN in a set window of time (e.g., $1 \mathrm{~min})$. Since $\mathrm{BC} 1_{\text {raw }}, \mathrm{BC} 2_{\text {raw }}, \mathrm{ATN} 1$ and ATN2 are all known variables, $\mathrm{eBC}_{\text {compensated }}$ and $k$ can be calculated for each measurement following Eqs. (5) and (6). As shown in Fig. S2 in the Supplement, $\mathrm{eBC} 1_{\text {raw }}$ and $\mathrm{eBC} 2_{\text {raw }}$ exhibit a discontinuity once the filter was moved to the next position, which implies biases induced by the loading effect. After the dual-spot correction, the discontinuity is minimized substantially as shown in Fig. S2.

It is worth noting that in the single-spot correction, $k$ is a constant in each spot cycle, which means all $\mathrm{eBC}_{\text {compensated }}$ values within the same cycle (e.g., a cycle lasts for several hours) have to share the same $k$. In contrast, time-resolved $k$ values can be determined for individual $\mathrm{eBC}_{\text {compensated }}$ in the dual-spot correction, which is a useful indicator for the mixing state (Drinovec et al., 2017). A zero test was conducted monthly for data quality control purposes.

The absorption Ångström exponent (AAE) can be determined by the multiwavelength measurement of AE33. AAE is a useful parameter to quantify the wavelength dependency of $\mathrm{BC}$ light absorption, as defined by the following equation (Moosmüller et al., 2011):

$\frac{\sigma_{\mathrm{abs}, \lambda_{1}}}{\sigma_{\mathrm{abs}, \lambda_{2}}}=\left(\frac{\lambda_{1}}{\lambda_{2}}\right)^{-\mathrm{AAE}}$,

where $\sigma_{\mathrm{abs}, \lambda_{1}}$ and $\sigma_{\mathrm{abs}, \lambda_{2}}$ are the light absorption coefficients at wavelengths of $\lambda_{1}$ and $\lambda_{2}$. The AAE of freshly emitted soot from vehicular emissions is close to 1 (Bond and Bergstrom, 2006; You et al., 2016). An increase in AAE could occur due to the coating of either $\mathrm{BrC}$ or non-absorbing materials. Samples that are strongly influenced by BB, which are generally rich in primary $\mathrm{BrC}$, can inflate AAE larger than 2 (Reid et al., 2005; Lewis et al., 2008; McMeeking et al., 2009; Pokhrel et al., 2016). Besides BB influence, an increase in AAE up to 1.5 due to the coating of non-absorbing materials on the BC particles has also been observed in both model simulations (Lack and Langridge, 2013) and laboratory experiments (You et al., 2016).

\subsection{OC and EC measurements}

A field carbon analyzer (model RT-4, Sunset Laboratory Inc, Tigard, Oregon, USA) was used for OC and EC determination. Detailed sampling procedures can be found in our previous study (Wu et al., 2019), and only a brief description is given here. The sample was collected in the first $45 \mathrm{~min}$ of each hour at a flow rate of $8 \mathrm{~L} \mathrm{~min}^{-1}$. The sample was analyzed in the next 15 min using thermo-optical analysis (Huntzicker et al., 1982). In the first stage, OC was vaporized by stepwise heating under helium $(\mathrm{He})$, which provides an oxygen-free environment. In the second stage, carrier gas was shifted to oxygen $\left(2 \% \mathrm{O}_{2}\right.$ in $\left.\mathrm{He}\right)$ to oxidize $\mathrm{EC}$ on the filter. The decomposition products of these two stages were converted to carbon dioxide $\left(\mathrm{CO}_{2}\right)$ by a manganese dioxide $\left(\mathrm{MnO}_{2}\right)$ catalyst, then detected by a nondispersive infrared absorption (NDIR) detector. The instrument blank was analyzed on a daily basis. The filter was changed every $6 \mathrm{~d}$ to minimized the bias due to the accumulation of refractory materials on the filter (Jung et al., 2011).

\subsection{Single-particle mass spectrometry measurements}

In the wet season, a single-particle aerosol mass spectrometer (SPAMS; Hexin Analytical Instrument Co., Ltd., China) was deployed at Jinan university atmospheric super site from 11 to 18 August 2017. In the dry season, SPAMS data (15 November to 27 December 2017) from Guangdong Environmental Monitoring Center (GDEMC) were used to characterize the EC-containing particles. The GDEMC site was located south to the JNU site $(4 \mathrm{~km})$. The operation principle of SPAMS has been introduced previously ( $\mathrm{Li}$ et al., 2011), and only a brief introduction is given here. The particles are introduced into the vacuum system through an $80 \mu \mathrm{m}$ critical orifice and then focused into a particle beam by the aerodynamic lens. As a result, the particles are accelerated to a size-dependent terminal velocity. The flight time of a known distance $(6 \mathrm{~cm})$ for individual particles is then detected by two orthogonally oriented continuous laser beams (Nd:YAG, $532 \mathrm{~nm}$ ) for particle size determination. Sized particles are individually vaporized and ionized by a $266 \mathrm{~nm}$ pulsed laser (Nd:YAG, $0.6 \mathrm{~mJ}$ ). The generated positive and negative ions are then detected by a $Z$-shaped bipolar time- 
of-flight mass spectrometer. SPAMS data analysis was performed by the Computational Continuation Core (COCO, V3.2) toolkit based on the MATLAB software. In total, 327453 and 2212688 particles with both positive and negative mass spectra were determined by the SPAMS in the wet and dry seasons, respectively. Based on the ion marker criteria shown in Table S2, 120351 and 595180 EC-containing particles were identified in the wet and dry season, respectively. EC-containing particles accounting for $37 \%$ and $27 \%$ of the total detected particles in the wet and dry season, respectively, which is comparable with a previous SPAMS study in Guangzhou (Zhang et al., 2015). EC-containing particles were further grouped into two categories, EC-fresh and EC-aged particles. EC-aged particles were extracted from EC-containing particles using the ion markers with the relative peak area (RPA) threshold listed in Table $\mathrm{S} 2$, including $-97\left[\mathrm{HSO}_{4}\right]^{-},-62\left[\mathrm{HNO}_{3}\right]^{-},-46\left[\mathrm{NO}_{2}\right]^{-}, 43\left[\mathrm{C}_{2} \mathrm{H}_{3} \mathrm{O}\right]^{+}$, etc. Once EC-aged particles were defined, the remaining ECcontaining particles are considered EC-fresh particles.

Despite the limitations in chemical composition quantification that is associated with the matrix effects induced by laser desorption/ionization, SPAMS is a unique technique that can provide chemical composition on a single particle level. The major advantage of single-particle analysis by SPAMS enables the characterization of coating materials exclusively on soot particles (K. Li et al., 2018), while bulk analytical techniques are incapable of distinguishing whether the non-EC materials are internally or externally mixed with EC. Relative peak area (RPA), which is defined as the peak area of each marker ion divided by the peak area of total ions, has been recognized as an indicator of the relative amount of a species on a particle (Gross et al., 2000; Jeong et al., 2011; Hatch et al., 2014; Zhou et al., 2016). Therefore, RPA is used in this study for SPAMS data analysis.

\subsection{Auxiliary measurements}

$\mathrm{NO}_{2}$ was determined by a chemiluminescence analyzer (model 42iTL, Thermo Scientific), while $\mathrm{O}_{3}$ was measured by a UV photometric analyzer (model 49i, Thermo Fisher Scientific, Waltham, MA, USA). Span and zero calibrations for the gas analyzers were performed automatically on a weekly basis. Meteorological factors were measured by a multiparameter sensor (model WXT 520, Vaisala, Vantaa, Finland). The planetary boundary layer height (PBLH) measurements were conducted by a micropulse lidar (Sigma Space Co., USA) at the Guangzhou Meteorological Bureau (GMB; $23.00^{\circ} \mathrm{N}, 113.32^{\circ} \mathrm{E}$; elevation: $43 \mathrm{~m}$ ). Hourly backward trajectories for the past $72 \mathrm{~h}$ were calculated using NOAA's HYSPLIT (HYbrid Single-Particle Lagrangian Integrated Trajectory, version 4) model (Draxier and Hess, 1998) for both dry and wet seasons. Backward trajectory cluster analysis was conducted using MeteoInfo (Wang, 2014, 2019). Fire count data from the Visible Infrared Imaging Radiometer Suite (VIIRS) aboard the
Suomi NPP weather satellite (Csiszar et al., 2014) were downloaded from the NASA FIRMS website (https://firms. modaps.eosdis.nasa.gov/, last access: 26 February 2020) to generate the fire count map.

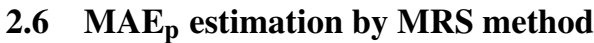

$\mathrm{MAE}_{\mathrm{p}}$ is the key parameter in the $E_{\mathrm{abs}}$ calculation. In this study, $\mathrm{MAE}_{\mathrm{p}}$ was determined by the newly developed MRS method (Wu et al., 2018), using EC as a tracer. The atmospheric aging-induced additional light absorption ( $\sigma_{\text {abs_aging }}$, which can be calculated by subtracting the absorption coefficient of primary aerosols, is shown in Eq. (8) (a combination of Eqs. 1 and 4):

$\sigma_{\text {abs_aging }}=\sigma_{\text {abs_total }}-\mathrm{MAE}_{\mathrm{p}} \times \mathrm{EC}$.

In the MRS calculation, the correlation $\left(R^{2}\right)$ between measured EC and estimated hypothetical $\sigma_{\text {abs_aging }}$ is examined as a function of a series of hypothetical $\mathrm{MAE}_{\mathrm{p}}\left(\mathrm{MAE}_{\mathrm{p} \_\mathrm{h}}\right)$. Since $\sigma_{\text {abs_aging }}$ results from secondary processing and EC comes from primary emissions, a $\mathrm{MAE}_{\mathrm{p} \_\mathrm{h}}$ that leads to a minimum $R^{2}\left(\mathrm{EC}, \sigma_{\text {abs_aging_h }}\right)$ can best represent the independent nature between EC and $\sigma_{\text {abs_aging. As a result, }}$ $\mathrm{MAE}_{\mathrm{p} \_\mathrm{h}}$ at minimum $R^{2}$ (EC, $\sigma_{\text {abs_aging_h }}$ ) corresponds to the authentic MAE $E_{p}$. The detailed method evaluation of MRS can be found in our previous paper (Wu et al., 2018). Only a brief description of the calculation steps is provided here. EC from the Sunset carbon analyzer and $\sigma_{\text {abs_total }}$ from the AE33 are used as input variables. During the calculation of $\mathrm{MAE}_{\mathrm{p}}$ by MRS, MAE $\mathrm{p}_{\mathrm{h}}$ is varied continuously in a reasonable range. At each $\mathrm{MAE}_{\mathrm{p} \_\mathrm{h}}$, corresponding hypothetical $\sigma_{\text {abs_aging }}\left(\sigma_{\text {abs_aging_h }}\right)$ values are calculated for the dataset, and a correlation coefficient value $\left(R^{2}\right)$ of EC vs. $\sigma_{\text {abs_aging_h }}$ (i.e., $R^{2}$ (EC, $\left.\sigma_{\text {abs_aging_h }}\right)$ ) is obtained. By searching the $\mathrm{MAE}_{\mathrm{p} \_\mathrm{h}}$ in the desired range (e.g., from 0.1 to 50 with an interval of 0.1$)$, a series of $R^{2}$ (EC, $\sigma_{\text {abs_aging_h }}$ ) values are then plotted against the $\mathrm{MAE}_{\mathrm{p} \_ \text {h }}$ values (Fig. 2), which only has a single minimum point.

The $\sigma_{\text {abs_pri }}$ is the part of light absorption from primary emitted soot particles. As a result, $\sigma_{\text {abs_pri }}$ is well correlated with EC mass. In contrast, $\sigma_{\text {abs_aging }}$ is the part of light absorption gained during the aging processes after emission. The variability in $\sigma_{\text {abs_aging mainly depends on the coating }}$ thickness of the soot particles. Consequently, $\sigma_{\text {abs_aging }}$ is independent of EC mass, and the $\mathrm{MAE}_{\mathrm{p} \_\mathrm{h}}$ corresponding to the minimum $R^{2}$ (EC, $\sigma_{\text {abs_aging_h }}$ ) would then represent the authentic $\mathrm{MAE}_{\mathrm{p}}$.

It is worth noting that $\mathrm{MAE}_{\mathrm{p}}$ by MRS represents the $\mathrm{MAE}_{\mathrm{p}}$ at the emission source, which is conceptually different from the $\mathrm{MAE}_{\mathrm{p}}$ by the TD method. First, the morphology and optical properties of freshly emitted BC particles (chainlike aggregates) are different from that of thermally denuded BC particles (compact aggregates). Second, most of the coatings are removed for TD denuded BC particles, but freshly emitted BC particles usually come with a thin coating of OC 
Wet season
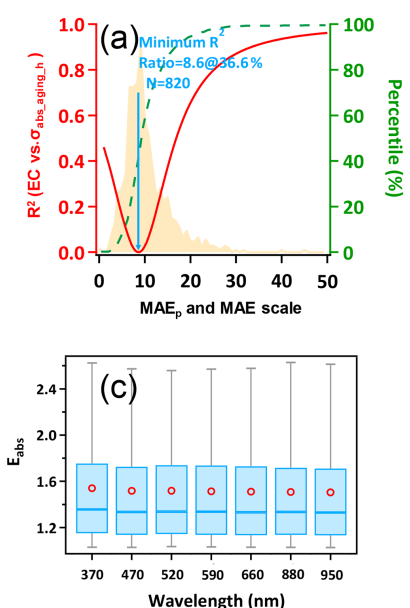

Dry season
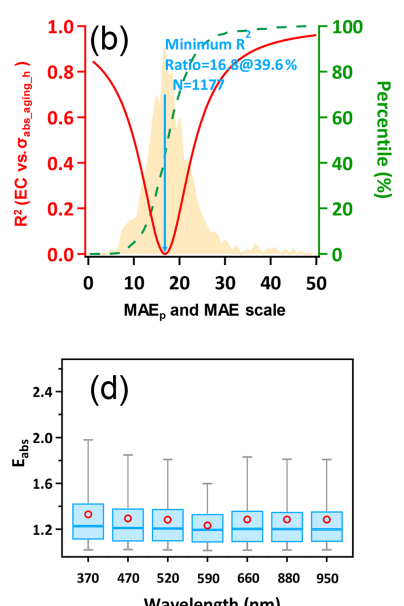

Figure 2. $E_{\text {abs }}$ determination by MRS. (a) Wet season MAE $\mathrm{p}_{\mathrm{p}}$ determined by MRS at $520 \mathrm{~nm}$. The red curve represents the correlation coefficient $\left(R^{2}\right)$ between hypothetical $\sigma_{\text {abs_aging }}\left(\sigma_{\text {abs total }}-\right.$ $\mathrm{EC} \cdot \mathrm{MAE}_{\mathrm{p}}$ ) and $\mathrm{EC}$ mass as a function of $\mathrm{MAE} \mathrm{E}_{\mathrm{p} \_\mathrm{h}}$. The shaded area in light tan represents the frequency distribution of observed MAE. The dashed green line is the cumulative distribution of observed MAE. (b) Same as (a) but for the dry season. (c) Spectral $E_{\text {abs }}$ determined by MRS in the wet season. Red circles represent the average values. The line inside the box indicates the median. Upper and lower boundaries of the box represent the 75th and the 25th percentiles; the whiskers above and below each box represent the 95 th and 5th percentiles. (d) Spectral $E_{\text {abs }}$ in the dry season.

formed from the condensation of organic vapors due to the temperature gradient from the flame to the ambient air. As a result, the MRS-derived $\mathrm{MAE}_{\mathrm{p}}$ is expected to be higher than the $\mathrm{MAE}_{\mathrm{p}}$ by the TD method.

\subsection{Secondary organic carbon (SOC) estimation by the MRS method}

OC can be separated into two categories based on the formation nature. Primary organic carbon (POC) can be emitted from traffic emission (Huang et al., 2014), biomass burning (Simoneit, 2002), trash burning and cooking (Mohr et al., 2009). Secondary organic carbon (SOC) can be formed through the oxidation of volatile organic compounds (VOCs) or semivolatile POC (Hallquist et al., 2009). The EC tracer method had been used extensively for SOC estimation (Turpin and Huntzicker, 1995):

$\mathrm{POC}=(\mathrm{OC} / \mathrm{EC})_{\text {pri }} \times \mathrm{EC}+\mathrm{OC}_{\text {non-comb }}$,

$\mathrm{SOC}=\mathrm{OC}_{\text {total }}-\mathrm{POC}$.

Combing Eqs. (9) and (10) gives the following:

$\mathrm{SOC}=\mathrm{OC}_{\text {total }}-(\mathrm{OC} / \mathrm{EC})_{\text {pri }} \times \mathrm{EC}-\mathrm{OC}_{\text {non-comb }}$,

where $(\mathrm{OC} / \mathrm{EC})_{\text {pri }}$ represents the overall $\mathrm{OC} / \mathrm{EC}$ ratio of aerosols from primary emission sources, while $\mathrm{OC}_{\text {non-comb }}$ represents primary $\mathrm{OC}$ from the non-combustion process. $\mathrm{OC}_{\text {non-comb }}$ can be determined from the intercept of $\mathrm{OC}$ vs. EC linear regression. In this study, weighted orthogonal distance regression (WODR) was used to account for errors in both $x$ and $y$ variables (Wu and $\mathrm{Yu}, 2018$ ). By grouping the data into percentile subsets using OC/EC ratio from the lowest to the highest (1\%-100\%, with an interval of $1 \%)$, a series of intercepts were obtained as a function of OC/EC percentile (Fig. S3). The intercept term in the OC vs. EC WODR is very small $(-0.88$ to -0.05$)$ throughout the percentile range $(1 \%-100 \%)$. Since this term is small, $\mathrm{OC}_{\text {non-comb }}$ was set to zero for SOC estimation in this study.

$(\mathrm{OC} / \mathrm{EC})_{\text {pri }}$ is the key parameter for SOC calculation in the EC tracer method. In the MRS method, the correlation $\left(R^{2}\right)$ between measured EC and estimated SOC (from Eq. 10) was examined as a function of a series of hypothetical $(\mathrm{OC} / \mathrm{EC})_{\text {pri }}\left((\mathrm{OC} / \mathrm{EC})_{\text {pri_h }}\right)$. The OC/EC ratio at the minimum $R^{2}$ (EC vs. SOC) corresponds to the authentic primary OC/EC ratio (Millet et al., 2005). The detailed calculation steps can be found in our previous paper (Wu and $\mathrm{Yu}, 2016$ ). Only a brief description is given here. In the MRS calculation, $(\mathrm{OC} / \mathrm{EC})_{\text {pri_h }}$ was varied continuously in a reasonable range (e.g., from 0.1 to 10 with an interval of 0.1 ). Hypothetical SOC $\left(\mathrm{SOC}_{\mathrm{h}}\right)$ values were calculated at individual $(\mathrm{OC} / \mathrm{EC})_{\text {pri_h }}$ for the whole dataset. A series of $R^{2}$ values of $\mathrm{EC}$ vs. $\mathrm{SOC}_{\mathrm{h}}$ (i.e., $\left.R^{2}\left(\mathrm{EC}, \mathrm{SOC}_{\mathrm{h}}\right)\right)$ were generated and then plotted against the $(\mathrm{OC} / \mathrm{EC})_{\text {pri_h }}$ values. Based on the assumption that variations in $\mathrm{EC}$ and SOC are independent, the $(\mathrm{OC} / \mathrm{EC})_{\text {pri_h }}$ corresponding to the minimum $R^{2}$ (EC, $\left.\mathrm{SOC}_{\mathrm{h}}\right)$ would then indicate the authentic $(\mathrm{OC} / \mathrm{EC})_{\text {pri }}$ ratio.

In our previous work, numerical studies were performed, and the results showed that the minimum $R$ squared method (MRS) is more robust in SOC estimation than the minimum OC/EC and percentile OC/EC methods (Wu and Yu, 2016). As a result, the MRS method had been gradually adopted for SOC estimation in recent studies (Xu et al., 2018b; Bian et al., 2018; Ji et al., 2018, 2019; Ying et al., 2018; Wu et al., 2019).

An Igor Pro-based computer program (WaveMetrics, Inc. Lake Oswego, OR, USA) (Wu and Yu, 2016) was used to implement the MRS calculation. Another two Igor Pro-based computer programs, Histbox (Wu et al., 2018) and Scatter Plot (Wu and $\mathrm{Yu}, 2018$ ), were used for generating the box plots and scatter plots presented in this study. These computer programs (with operation manuals) can be downloaded freely from https://sites.google.com/site/wuchengust (last access: 26 February 2020). 


\section{Results and discussions}

\subsection{Seasonality of carbonaceous aerosol concentrations and optical properties}

The time series of EC, OC, optical properties and supporting measurements during the wet and dry seasons are shown in Fig. S4. The hourly EC concentrations ranged from 0.43 to 7.40 and 0.54 to $12.04 \mu \mathrm{gC} \mathrm{m}^{-3}$ in the wet and dry seasons, respectively. As for $\mathrm{OC}$, the hourly average ranged from 0.32 to 13.84 and 0.51 to $25.31 \mu \mathrm{gC} \mathrm{m}{ }^{-3}$ in the wet and dry seasons, respectively. The hourly $\mathrm{OC} / \mathrm{EC}$ ratios ranged from 0.25 to 6.92 and 0.33 to 8.69 in the wet and dry seasons, respectively. In the wet season, the wind direction is southeasterly dominated, bringing the relatively clean background air masses from the vast ocean. In the dry season, the northeasterly wind prevails, which promotes the long-range transport of air pollutants from eastern and central China.

As shown in Fig. 1, EC, OC and OC/EC AAE $470-660$ all exhibit clear seasonality. Average EC concentrations (with 1 standard deviation, hereafter) were $1.94 \pm 0.93$ and $2.81 \pm$ $2.01 \mathrm{\mu g} \mathrm{m}^{-3}$ in the wet and dry seasons, respectively. The EC level was comparable to the measurements made in 2012 at a Guangzhou suburban site $\left(1.67 \pm 1.35 \mu \mathrm{gC} \mathrm{m}^{-3}\right.$ in the wet season, $3.47 \pm 2.75 \mu \mathrm{gC} \mathrm{m}^{-3}$ in the dry season) (Wu et al., 2019).

The average concentrations of OC doubled in the dry season $\left(7.02 \pm 5.19 \mu \mathrm{gC} \mathrm{m}^{-3}\right)$ compared to those in the wet season $\left(3.38 \pm 1.93 \mu \mathrm{gC} \mathrm{m}^{-3}\right)$, leading to elevated OC/EC ratio in the dry season $(2.56 \pm 0.94)$ in contrast to wet season $(1.78 \pm 0.83)$. The hourly $\mathrm{AAE}_{470-660}$ ranged from 1.14 to 1.67 and 1.07 to 1.76 in the wet and dry seasons, respectively. As shown in Fig. S5a, AAE $470-660$ observed in the dry season $(1.46 \pm 0.12)$ was significantly $(P<0.001)$ higher than that in the wet season $(1.37 \pm 0.10)$.

Measured $\mathrm{MAE}_{520}$ in the dry season $\left(18.47 \pm 5.49 \mathrm{~m}^{2} \mathrm{~g}^{-1}\right)$ is significantly $(P<0.001)$ higher than that in the wet season $\left(10.73 \pm 4.96 \mathrm{~m}^{2} \mathrm{~g}^{-1}\right)$, as shown in Fig. S5b. The elevated MAE during the dry season was likely a result of BB influences, which will be discussed in detail in Sect. 3.3.

The $\mathrm{MAE}_{\mathrm{p} 520}$ values determined by MRS were 8.6 and $16.8 \mathrm{~m}^{2} \mathrm{~g}^{-1}$, for wet and dry seasons, respectively (Fig. 2a and b). Similar to $\mathrm{MAE}_{520}$, the increase in $\mathrm{MAE}_{\mathrm{p} 520}$ in the dry season was also likely a result of $\mathrm{BB}$ influence, which could lead to larger BC cores (Ditas et al., 2018) and with thicker primary coatings (Schwarz et al., 2008a; Kondo et al., 2011; Lack et al., 2012a; Liu et al., 2014). More details of the BB influences will be discussed in Sect. 3.3. Consequently, light absorption enhancement was found to be more pronounced in the wet season $\left(E_{\mathrm{abs} 520}=1.51 \pm 0.50\right.$, Table 2) than in dry season $(1.29 \pm 0.28)$, because $E_{\text {abs }}$ depends on the ratio of MAE to $\mathrm{MAE}_{\mathrm{p}}$, not their absolute values.

In summary, as evidenced by AAE $470-660$ and MAE results, carbonaceous aerosols exhibit strong seasonality in urban Guangzhou. This seasonality was associated with two seasonal factors, including the contrasted direction of the prevailing wind and diverse primary $\mathrm{BC}$ optical properties induced by seasonal BB influence.

\subsection{Comparison of $E_{\text {abs }}$ with previous studies}

Field measurements of $E_{\text {abs }}$ values around the world are summarized in Table 2. Studies using the TD approach can achieve a sub-hour time resolution, but studies using the TD approach had limited temporal coverage (normally less than a month). The AFD approach can potentially provide longterm $E_{\text {abs }}$ results as long as filter samples are available. However, the measurement duration of existing AFD studies was less than 1 month as shown in Table 2. The limited temporal coverage of existing AFD studies was likely due to the intense labor involved in filter treatment. In addition, the time resolution of existing AFD studies (8-24h) was not sufficient to fully resolve $E_{\text {abs }}$ diurnal pattern. As a result, diurnal variations of $E_{\text {abs }}$ values for different seasons were not covered in previous studies. In comparison, the MRS approach is a good alternative to explore the $E_{\mathrm{abs}}$ variations at both seasonal and diurnal scales. As shown in Table 2, low $E_{\text {abs }}$ values were found in California (1.06 at $532 \mathrm{~nm}$ ) (Cappa et al., 2012) and Japan (1.06 at $532 \mathrm{~nm}$ ) (Ueda et al., 2016). D. Liu et al. (2017) observed moderate $E_{\text {abs }}$ in the UK (1.0-1.3 at $532 \mathrm{~nm})$ and suggested that the small $E_{\text {abs }}$ observed by Cappa et al. (2012) was a result of mixing state diversity. A recent study in California (Cappa et al., 2019) found moderate $E_{\text {abs }}$ at Fresno $(1.22$ at $532 \mathrm{~nm})$ but low $E_{\text {abs }}$ at Fontana (1.07 at $532 \mathrm{~nm}$ ), which was partially associated with an unequal distribution of coating between different BC-containing particle types (Lee et al., 2019). In general, higher $E_{\text {abs }}$ values have been observed in more polluted urban areas, such as France (Paris, 1.53 at $880 \mathrm{~nm}$ ) (Zhang et al., 2018a) and India (Kanpur, 1.8 at $781 \mathrm{~nm}$ ) (Thamban et al., 2017). High $E_{\text {abs }}$ values have been reported in various locations in China. The $E_{\text {abs }}$ value in the wet season in our study (1.51) is higher than that in Nanjing (1.42) (Ma et al., 2020) but lower than those in central China (Shouxian, 2.3) (Xu et al., 2018), eastern China (Jinan, 1.9) (Bai et al., 2018) and northern China (Yuncheng, 2.25) (X. Cui et al., 2016). The $E_{\text {abs }}$ value in the dry season in our study (1.29) is lower than those in other locations in China, such as Beijing (1.664.0) (Xu et al., 2016; Zhang et al., 2018b), Nanjing (1.6) (F. Cui et al., 2016), Xi' an (1.8) (Wang et al., 2014) and Jinan (2.07) (Chen et al., 2017). Since the colocated comparison of the three $E_{\text {abs }}$ methods does not exist, a direct comparison between the three methods remains difficult. Nevertheless, a few studies, which conducted in the same city but during different periods, yielded comparable $E_{\text {abs }}$ values. For example, $E_{\text {abs }}$ in Nanjing by the MAE method (1.6) (F. Cui et al., 2016) was higher than that by the TD method (1.42) (Ma et al., 2020). This difference in $E_{\text {abs }}$ might not only be due to the different $E_{\text {abs }}$ determination methods but also could be a result of seasonal variations in $E_{\text {abs }}$. 
Table 2. Comparisons of $E_{\mathrm{abs}}$ measurements in various field studies.

\begin{tabular}{|c|c|c|c|c|c|c|c|}
\hline Approach & Location & Sampling period & $\begin{array}{l}\text { Sampling } \\
\text { duration }\end{array}$ & $\begin{array}{l}\text { Time } \\
\text { resolution }\end{array}$ & $\begin{array}{l}\lambda \\
(\mathrm{nm})\end{array}$ & $E_{\text {abs }}$ & Reference \\
\hline \multirow[t]{2}{*}{$\begin{array}{l}\text { MAE + } \\
\text { MRS }\end{array}$} & $\begin{array}{l}\text { Guangzhou, China } \\
\text { (urban) }\end{array}$ & $\begin{array}{l}\text { Jul-Sep } 2017 \\
\text { Nov 2017-Jan } 2018\end{array}$ & 6 months & $1 \mathrm{~h}$ & 520 & $\begin{array}{l}1.51 \pm 0.50 \\
1.29 \pm 0.28\end{array}$ & This study \\
\hline & $\begin{array}{l}\text { Guangzhou, } \\
\text { China } \\
\text { (suburban) }\end{array}$ & Feb 2012-Jan 2013 & 1 year & $1 \mathrm{~h}$ & 550 & $1.50 \pm 0.48$ & Wu et al. (2018) \\
\hline \multirow[t]{2}{*}{$\begin{array}{l}\mathrm{MAE}+ \\
\text { empirical }\end{array}$} & $\begin{array}{l}\text { Nanjing, China } \\
\text { (suburban) }\end{array}$ & Nov 2012 & $15 d$ & $12 \mathrm{~h}$ & 532 & 1.6 & F. Cui et al. (2016) \\
\hline & $\begin{array}{l}\text { Beijing, China } \\
\text { (suburban) }\end{array}$ & Nov 2014-Jan 2015 & 2 months & $1 \mathrm{~h}$ & 470 & $2.6-4.0$ & Xu et al. (2016) \\
\hline \multirow[t]{5}{*}{$\begin{array}{l}\mathrm{MAE}+ \\
\mathrm{SP}\end{array}$} & $\begin{array}{l}\text { Beijing, China } \\
\text { (urban) }\end{array}$ & Nov 2014 & $14 d$ & $1 \mathrm{~h}$ & 880 & $1.66-1.91$ & Zhang et al. (2018b) \\
\hline & $\begin{array}{l}\text { Manchester, UK } \\
\text { (urban) }\end{array}$ & Oct-Nov 2014 & $13 \mathrm{~d}$ & $5 \min$ & 532 & $1.0-1.3$ & D. Liu et al. (2017) \\
\hline & $\begin{array}{l}\text { Paris, France } \\
\text { (urban) }\end{array}$ & Mar 2014-Mar 2017 & 3 years & $24 \mathrm{~h}$ & 880 & $1.53 \pm 0.39$ & Zhang et al. (2018a) \\
\hline & $\begin{array}{l}\text { Kanpur, India } \\
\text { (urban) }\end{array}$ & Jan-Feb 2015 & 2 months & $1 \mathrm{~h}$ & 781 & 1.8 & Thamban et al. (2017) \\
\hline & $\begin{array}{l}\text { Xi'an, China } \\
\text { (urban) }\end{array}$ & Dec 2012-Jan 2013 & 1 month & $20 \mathrm{~min}$ & 870 & 1.8 & Wang et al. (2014) \\
\hline \multirow[t]{7}{*}{ TD } & $\begin{array}{l}\text { Shouxian, China } \\
\text { (Rural) }\end{array}$ & Jun-Jul 2016 & $8 \mathrm{~d}$ & $10 \mathrm{~min}$ & 532 & $2.3 \pm 0.9$ & Xu et al. (2018) \\
\hline & $\begin{array}{l}\text { Beijing, China } \\
\text { (urban) }\end{array}$ & Jun 2017 & $10 \mathrm{~d}$ & $20 \mathrm{~min}$ & 630 & $1.59 \pm 0.26$ & Xie et al. (2019) \\
\hline & $\begin{array}{l}\text { Sacramento, USA } \\
\text { (urban) }\end{array}$ & Jun-Jul 2010 & $13 \mathrm{~d}$ & $20 \mathrm{~min}$ & 532 & $1.06 \pm 0.01$ & Cappa et al. (2012) \\
\hline & $\begin{array}{l}\text { Fresno, USA } \\
\text { (urban) }\end{array}$ & Dec 2014-Jan 2015 & $19 \mathrm{~d}$ & \multirow{2}{*}{$10 \mathrm{~min}$} & 532 & $1.22 \pm 0.15$ & \multirow{2}{*}{ Cappa et al. (2019) } \\
\hline & $\begin{array}{l}\text { Fontana, USA } \\
\text { (urban) }\end{array}$ & July 2015 & $23 \mathrm{~d}$ & & 532 & $1.07 \pm 0.22$ & \\
\hline & Suzu, Japan & Apr-May 2013 & $26 \mathrm{~d}$ & $20 \mathrm{~min}$ & 532 & 1.06 & Ueda et al. (2016) \\
\hline & $\begin{array}{l}\text { Nanjing, China } \\
\text { (suburban) }\end{array}$ & Aug-Sep 2014 & $16 \mathrm{~d}$ & $2 \mathrm{~h}$ & $\begin{array}{l}405 \\
532 \\
781\end{array}$ & $\begin{array}{l}1.41 \pm 0.39 \\
1.42 \pm 0.40 \\
1.35 \pm 0.38\end{array}$ & Ma et al. (2020) \\
\hline \multirow[t]{4}{*}{ AFD } & $\begin{array}{l}\text { Jinan, China } \\
\text { (urban) }\end{array}$ & Feb 2014 & $13 \mathrm{~d}$ & $8 \mathrm{~h}$ & 678 & $2.07 \pm 0.72$ & Chen et al. (2017) \\
\hline & $\begin{array}{l}\text { Yuncheng, China } \\
\text { (rural) }\end{array}$ & Jun-Jul 2014 & $18 \mathrm{~d}$ & $12 \mathrm{~h}$ & 678 & $2.25 \pm 0.55$ & X. Cui et al. (2016) \\
\hline & $\begin{array}{l}\text { Jinan, China } \\
\text { (urban) }\end{array}$ & Jul-Jul 2016 & $30 \mathrm{~d}$ & $24 \mathrm{~h}$ & 678 & $1.9 \pm 0.7$ & \multirow{2}{*}{ Bai et al. (2018) } \\
\hline & $\begin{array}{l}\text { Mt. Tai, China } \\
\text { (rural) }\end{array}$ & Jul-Aug 2014 & $31 \mathrm{~d}$ & $24 \mathrm{~h}$ & 678 & $2.0 \pm 0.3$ & \\
\hline
\end{tabular}




\subsection{Influence of biomass burning on the BC optical properties during the dry season}

Evidence from particle chemical compositions showed that the BB influence was more intense in the dry season. Levoglucosan had been widely accepted as a tracer for BB in $\mathrm{PM}_{2.5}$ (Engling et al., 2006; Bhattarai et al., 2019). As shown in Fig. S6, levoglucosan concentrations in Guangzhou were elevated by 1 order of magnitude during the dry season $\left(159.33 \mathrm{ng} \mathrm{m}^{-3}\right)$ compared to those in the wet season (35.93 $\mathrm{n} \mathrm{m}^{-3}$ ). Besides levoglucosan, the primary OC/EC ratio can also be used as an indicator of $\mathrm{BB}$ influence since the BB-influenced samples have a higher $\mathrm{OC} / \mathrm{EC}$ ratio than those from traffic emissions (Schmidl et al., 2008; Pokhrel et al., 2016). In this study, (OC/EC) pri determined by MRS in the dry season (2.31) was higher than that in the wet season (1.49), as shown in Fig. S7. In addition, the northeasterly wind prevailed during the dry season, which favors longrange transport of aerosols from BB from central and eastern China to the PRD region. Remote sensing results also confirmed the more intense BB in the dry season, as shown by the gridded fire count map (Fig. S8) determined by VIIRS.

As a result, the optical properties of $\mathrm{BC}$ were largely affected by the intense BB influences during the dry season. First, as shown in Fig. S5b, a significantly $(P<0.001)$ higher $\mathrm{MAE}_{520}$ was observed in the dry season $(18.47 \pm 5.49)$ compared to that in the wet season (11.28 \pm 9.88$)$. A previous field study at a suburban site in Guangzhou also reported the influence of $\mathrm{BB}$ on MAE, which observed a positive correlation between $\mathrm{K}^{+}$and MAE (Wu et al., 2018). High MAE from BB had been reported in BB emission studies as well (Roden et al., 2006; Schmidl et al., 2008; Levin et al., 2010; Wang et al., 2018a). Single-particle soot photometer (SP2) studies have shown that BB-influenced BC particles are more likely to have larger BC cores (Ditas et al., 2018) and have thicker initial coatings than those from vehicular emissions (Schwarz et al., 2008a; Kondo et al., 2011; Lack et al., 2012a; Liu et al., 2014). This is in good agreement with the $\mathrm{MAE}_{\mathrm{p} 520}$ obtained in the present study, which was almost doubled in the dry season $\left(16.8 \mathrm{~m}^{2} \mathrm{~g}^{-1}\right)$ compared to that in the wet season $\left(8.6 \mathrm{~m}^{2} \mathrm{~g}^{-1}\right)$.

In the dry season the $E_{\text {abs }}$ showed little wavelength dependence (Fig. 2d) despite the influence of BB. In this sense, the BB influence did substantially alter the optical properties of primary $\mathrm{BC}$ in the dry season, but the contribution of secondary $\mathrm{BrC}$ to $E_{\mathrm{abs}}$ was likely limited. The weak wavelength dependence of $E_{\text {abs }}$ has also been observed in a previous study at a suburban site in Guangzhou (Wu et al., 2018). A previous study in Guangzhou also found that the seasonal difference in $\mathrm{BrC}$ light absorption contribution at $405 \mathrm{~nm}$ between dry season (15\%-19\%) and wet seasons (12\%$15 \%$ ) was small (S. Li et al., 2018). In addition, the small seasonal difference of AAE between wet $(1.37 \pm 0.10)$ and dry $(1.46 \pm 0.12)$ seasons observed in this study also implies that the secondary $\mathrm{BrC}$ contribution was not the dominating driver for AAE deviation from 1, which was the typical AAE for fresh soot without atmospheric aging. The results found in the PRD were in contrast to a study in Paris, which found systematically higher $E_{\mathrm{abs} 370}$ than $E_{\mathrm{abs} 880}$ at wintertime due to the influence of BB (Zhang et al., 2018a). This discrepancy implies the complex linkage between $\mathrm{BB}$ and $\mathrm{BrC}$ optical properties.

The complex relationship between $\mathrm{AAE}$ and $\mathrm{BrC}$ can be affected by a variety of factors. First, the optical properties of primary $\mathrm{BrC}$ from $\mathrm{BB}$ exhibit a large diversity in previous studies (Martinsson et al., 2015; J. Tian et al., 2019), which can be affected by fuel type and combustion conditions (Reid et al., 2005; Roden et al., 2006). Second, atmospheric aging can lead to AAE elevation through the formation of secondary $\mathrm{BrC}$ from a variety of pathways (Moise et al., 2015; Laskin et al., 2015), including nitration of aromatic compounds (Jacobson, 1999), reaction of ammonia (Bones et al., 2010), bond-forming reactions between SOA constituents (Shapiro et al., 2009), reactions of BB products (Gilardoni et al., 2016; Kumar et al., 2018), photo-enhancement (Hems and Abbatt, 2018; J. Liu et al., 2016; Ye et al., 2019), and aqueous-phase reactions (Lin et al., 2015; Tang et al., 2016; Xu et al., 2018a). On the other hand, AAE decrease could also occur during atmospheric aging (Romonosky et al., 2019), either induced by photobleaching of $\mathrm{BrC}$ (Adler et al., 2011; Zhong and Jang, 2011, 2014; Lee et al., 2014; Canonaco et al., 2015; Lin et al., 2016; Sumlin et al., 2017; Bhattarai et al., 2018; Fortenberry et al., 2018; Hems and Abbatt, 2018; Browne et al., 2019; Dasari et al., 2019; C. Li et al., 2019; Wong et al., 2019; Cai et al., 2019; Liakakou et al., 2019; Ray et al., 2019) or aqueous-phase BrC degradation in the absence of light (Santos and Duarte, 2015; G. T. A. D Santos et al., 2016; P. S. M. Santos et al., 2016; Fan et al., 2019). The relative contribution of secondary $\mathrm{BrC}$ formation and $\mathrm{BrC}$ degradation to the total $\mathrm{BrC}$ light absorption budget is still poorly understood. $\mathrm{BrC}$ degradation could be one of the reasons for the small seasonal AAE difference observed in the PRD region. More studies are needed by incorporating both time-resolved optical measurements and time-resolved detailed chemical speciation measurements to better understand the balance of $\mathrm{BrC}$ formation and degradation.

\subsection{Diurnal dynamics of carbonaceous aerosols concentrations and optical properties}

The diurnal variations in EC, OC, OC/EC, SOC, $\mathrm{AAE}_{470-660}$ and $E_{\text {abs520 }}$ in the wet and dry seasons are shown in Fig. 3. Two peaks can be observed for EC (Fig. 3a): one in the early morning (07:00 LT, UTC +8 , all times in this paper are local time) and the other in the evening (19:00), which reflects local traffic emissions in two rush hours. The lowest EC was found in the afternoon (14:00), likely associated with two factors considering the nature of EC source exclusive from primary emissions. The first factor is the planetary boundary 


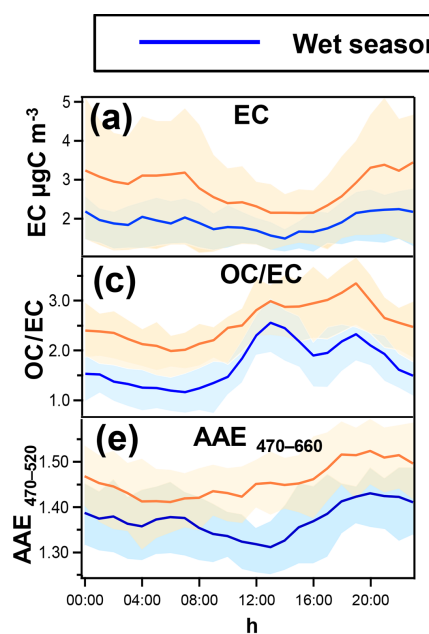

Dry season

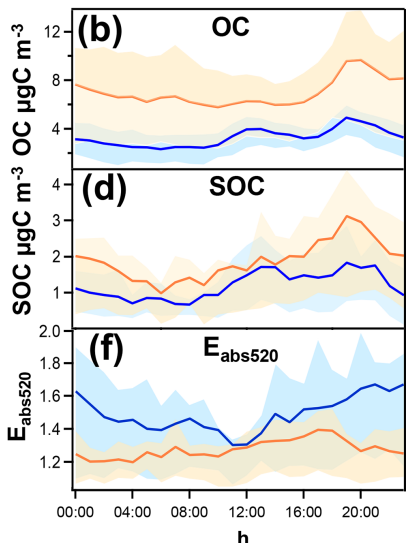

Figure 3. Diurnal pattern carbonaceous aerosols in the wet and dry seasons. The solid lines represent hourly averages and the shaded areas represent 25 th and 75 th percentiles. (a) EC. (b) OC. (c) OC/EC ratio. (d) SOC. (e) AAE $470-660$. (f) $E_{\text {abs520 }}$.

layer (PBL) height. As shown in Fig. S9, the diurnal maximum PBL height was at 14:00 and 15:00 for wet and dry seasons, respectively. The fully developed PBL would help dilute the concentrations of primary pollutants (Deng et al., 2016; Liu et al., 2019; Williams et al., 2019). The second factor is the diurnal variations of traffic volume. Previous studies (Yao et al., 2013; Xie et al., 2003) showed that traffic volume during 12:00-15:00 is lower than that in the morning and evening rush hours. To explore the effect of traffic volume, the weekday/weekend effect was investigated in Fig. S10. The evening EC peak reduced substantially during the weekend, implying that traffic volume has a strong influence on shaping the diurnal pattern of EC. The combination of these two factors leads to reduced EC concentrations in the afternoon. The diurnal pattern of EC is similar between wet and dry seasons, but the magnitude was greatly elevated in the dry season.

OC exhibits a bimodal distribution (Fig. 3b), peaking at 13:00 and 19:00, respectively. OC can be both primary and secondary, making its diurnal pattern different from that of EC. OC/EC also has two peaks as shown in Fig. 3c. The first peak appeared at 13:00 and the second peak showed up at 17:00. It is worth noting that in the wet season the afternoon OC/EC peak was higher than that in the evening OC/EC peak, while in the dry season the reverse is true. The difference in diurnal OC/EC pattern between weekday and weekend is negligible (Fig. S10), suggesting that the proportion of different vehicle types (e.g., diesel vs. gasoline) is relatively constant between weekday and weekend.

As shown in Fig. 3d, two SOC peaks are observed in the wet season, with the first SOC peak at 13:00 and the second SOC peak at 19:00. In the dry season the afternoon SOC peak was merged into the broadened evening peak. Despite

the higher SOC concentrations observed in the dry season, SOC formation was more active during the wet season as evidenced by the diurnal SOC/OC ratios (Fig. 4a). The diurnal $\mathrm{SOC} / \mathrm{OC}$ ratio in the wet season was always higher than that in the dry season. It is worth noting that in the wet season, despite the fact that the SOC evening peak was comparable to the afternoon peak as shown in Fig. 3d, the SOC/OC evening peak was smaller than the afternoon peak (Fig. 4a). This observation implies that the SOC evening peak in the wet season is a result of the combination of pollutant accumulation (e.g., PBL decrease after sunset) and SOC formation rather than the formation process alone. The small evening peak of SOC/OC in summer (19:00-21:00) would also be likely a result of condensation of semivolatile organic compounds (Warren et al., 2009; Pathak et al., 2008; Liang et al., 1997) due to the temperature decrease after sunset.

SOC/OC dependence on RH was investigated (Fig. S11) to explore the effect of aqueous-phase secondary organic aerosol formation. During the wet season, SOC/OC decreases as RH increases and the results were the same for both daytime and nighttime (Fig. S11a and b). During nighttime when no solar radiation was supplied, higher RH leads to a lower SOC/OC (Fig. S11b). This piece of evidence suggests that aqueous-phase reactions were unlikely the dominating pathway for SOC formation during the wet season. In the dry season, SOC/OC does not show a clear dependence on $\mathrm{RH}$, suggesting that $\mathrm{SOC}$ formation is not sensitive to $\mathrm{RH}$ in the dry season.

The diurnal trend of AAE $_{470-660}$ was similar between wet and dry seasons, which is higher in the evening and lower during midday, but the magnitude of $\mathrm{AAE}_{470-660}$ slightly increased during the dry season. The $E_{\text {abs520 }}$ exhibits different diurnal patterns between the wet and dry seasons. As shown in Fig. 5, elevated $E_{\text {abs520 }}$ was found during nighttime in the wet season, but in dry season inflated $E_{\text {abs520 }}$ was observed in the afternoon. In addition, the degree of light absorption enhancement was more pronounced in the wet season. The influencing factors of dynamics are discussed in the following sections.

\subsection{The diurnal correlations between AAE, $k$ and $E_{\text {abs }}$}

The loading effect correction factor used in AE33, $k$, has been found to be a useful indicator for the light absorption enhancement of BC (Drinovec et al., 2017). As shown in Fig. 5a, in the wet season a good anticorrelation was found between $k_{3}$ ( $k$ value for $520 \mathrm{~nm}$ ) and $E_{\text {abs520 }}$ with an $R^{2}$ of 0.74 . In the dry season, such an anticorrelation was substantially weakened $\left(R^{2}=0.20\right)$ as shown in Fig. 5 b, likely due to the influence of BB. These results agree well with the findings reported by Drinovec et al. (2017) that $k$ can be used as a $\mathrm{BC}$ particle coating indicator without the influence of BB. As shown in Fig. 5a, a good correlation was found for $\mathrm{AAE}_{470-660}$ with $E_{\mathrm{abs} 520}\left(R^{2}=0.71\right)$. Considering the weak BB influence in the wet season as discussed in Sect. 3.3, 
(a) Wet season

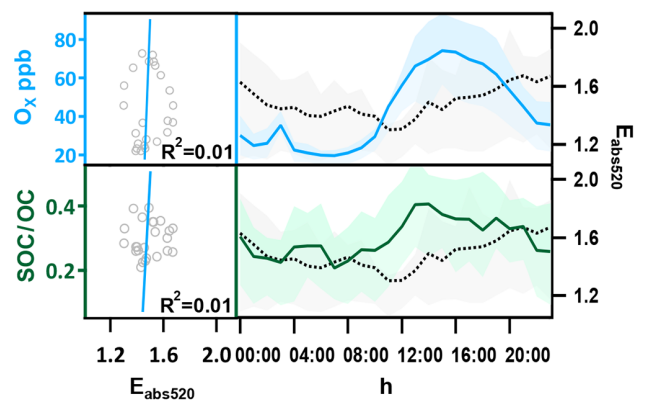

(b) Dry season

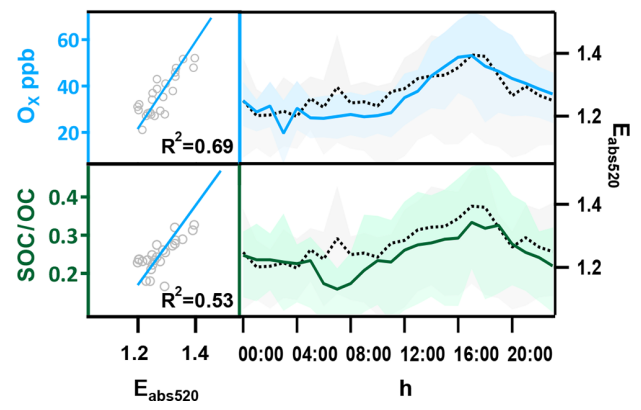

Figure 4. The effect of the secondary process on $E_{\mathrm{abs} 520}$. (a) Diurnal pattern of $E_{\mathrm{abs} 520}$ and $\mathrm{O}_{x}$ in the wet season. The lines $\left(\mathrm{O}_{x}\right.$ in blue,

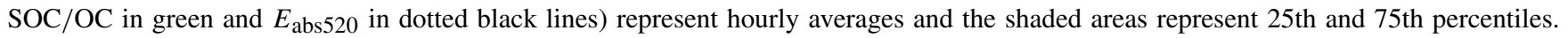
(b) Same as (a) but in the dry season.

(a) Wet season

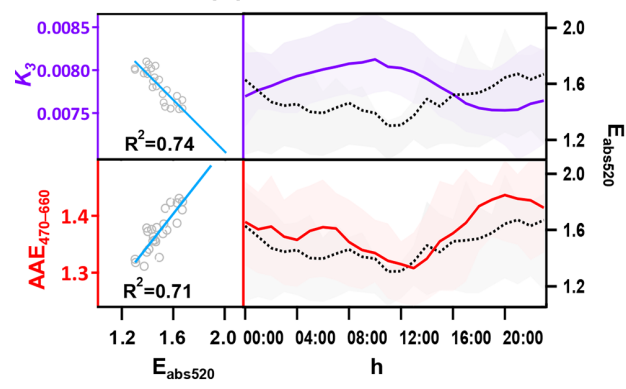

(b) Dry season

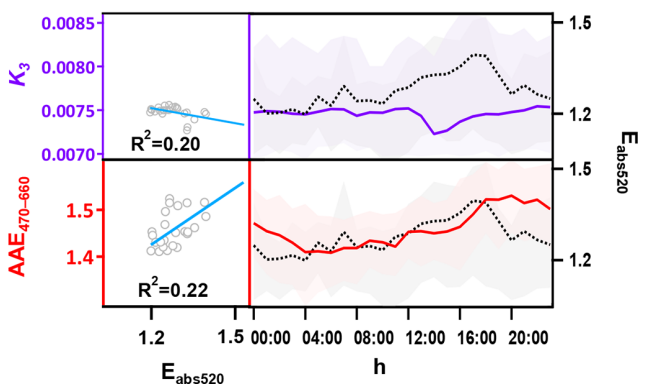

Figure 5. Diurnal patterns of $E_{\mathrm{abs520}}, \mathrm{AAE}_{470-660}$ and $k_{3}$. The lines ( $k_{3}$ in purple, $\mathrm{AAE}_{470-660}$ in red and $E_{\text {abs520 }}$ in dotted black lines) represent hourly averages and the shaded areas represent 25 th and 75 th percentiles. (a) Wet season. (b) Dry season.

the atmospheric aging-induced coating on $\mathrm{BC}$ particles was more likely the dominating driver of $\mathrm{AAE}_{470-660}$ dynamics during the wet season in the PRD region. The presence of a coating of $\mathrm{BC}$ could also explain that despite the fact that the $\mathrm{BB}$ influence is small in the wet season, the observed average $\mathrm{AAE}(1.37 \pm 0.10)$ was significantly higher than the AAE of fresh $\mathrm{BC}(\sim 1)$. This result is also consistent with previous studies that found that a non-light-absorbing coating can lead to elevated AAE up to 1.5 (Lack and Cappa, 2010; Lack and Langridge, 2013). In the dry season, the variability in AAE was governed by both coating thickness and BB influence, thus leading to a degraded $R^{2}(0.22)$ between $\mathrm{AAE}_{470-660}$ and $E_{\text {abs520 }}$ as shown in Fig. 5b. A recent study showed that the diurnal pattern of $\mathrm{BrC}$ was moderately correlated with a $\mathrm{BB}$ tracer, $\mathrm{K}^{+}$, in the PRD region during the dry season (Z. Li et al., 2019), implying that BB did have a considerable influence on AAE viability during the dry season.

The spectral fingerprints of $k$ were shown in Fig. S12. Observations in Europe showed that the presence of $\mathrm{BrC}$ could lead to increased $k$ at longer wavelengths (Drinovec et al., 2017). Our observations showed that the seasonal difference in spectral fingerprints of $k$ between wet and dry seasons is small. Considering the limited increase in AAE in the dry season and the similarity of seasonal spectral fingerprints of $k$, these results suggest that, in the PRD region, despite the fact that the BB influence in the dry season effectively altered the optical properties of $\mathrm{BC}$ aerosols, there was a likely limited secondary $\mathrm{BrC}$ contribution to $E_{\text {abs }}$ during the dry season, which is in agreement with discussions in Sect. 3.3.

\subsection{The influence of secondary processing on $\mathbf{E}_{a b s}$ diurnal dynamics}

Photochemical reactions play an important role in the aging process of black carbon, leading to the modification of $\mathrm{BC}$ morphology and optical properties as evidenced by laboratory studies (Saathoff et al., 2003; Schnaiter et al., 2005; Martinsson et al., 2015; Pei et al., 2018) and quasi-atmospheric chamber studies (Peng et al., 2017, 2016). Field studies at various locations have also showed that photochemical processing can promote the light absorption enhancement of BC, including in Beijing (Liu et al., 2019a), the Yangtze River Delta (Xu et al., 2018), Xi' an (Wang et al., 2017), Los Angeles (Krasowsky et al., 2016) and Toronto (Knox et al., 2009). The concentration of odd oxygen $\left(\mathrm{O}_{x}=\mathrm{O}_{3}+\mathrm{NO}_{2}\right)$ proposed by Liu (1977) and (Levy II et al., 1985) has been widely used as the indicator of photochemical aging. In this study, the diurnal correlations between $\mathrm{O}_{x}$ and $E_{\text {abs520 }}$ were investigated to explore the effect of photochemical processing. As shown 
in Fig. $4 \mathrm{a}$, in the wet season $\mathrm{O}_{x}$ and $E_{\text {abs520 }}$ peaked at 15:00 and 00:00, respectively. The $\mathrm{O}_{x}$ experienced a continuous decline from 15:00 until sunrise of the next day, but the growth of $E_{\text {abs }}$ extended to midnight. The nighttime $E_{\text {abs520 }}$ peak suggests that the increase in coating can be achieved without the presence of solar radiation. These differences in the diurnal patterns led to a low correlation between $\mathrm{O}_{x}$ and $E_{\text {abs }}$ $\left(R^{2}=0.01\right)$. This result implies that in the wet season the diurnal variability in $E_{\text {abs } 520}$ was unlikely dominated by photochemical reactions, despite the fact that $\mathrm{O}_{x}$ was more pronounced in the wet season. As for the dry season (Fig. 4b), both $\mathrm{O}_{x}$ and $E_{\text {abs520 }}$ peaked at 17:00, leading to a good correlation with a $R^{2}$ of 0.69 , suggesting that photochemical reactions could be one of the main drivers for $E_{\text {abs }}$ diurnal variations. This result strongly indicates that $\mathrm{BC}$ light absorption can be markedly amplified through photochemical reactions. Our dry-season results are consistent with a previous study in northern China (Wang et al., 2017), which also showed the dependence of light absorption enhancement on $\mathrm{O}_{x}$ during the wintertime.

In the meantime, the formation of SOC also contributes to light absorption enhancement of BC, which had been observed in both field studies (Moffet and Prather, 2009; Wang et al., 2017a; Zhang et al., 2018a) and laboratory studies (Schnaiter et al., 2005; Lambe et al., 2013; Saliba et al., 2016). In this study, the effect of SOC formation on $E_{\text {abs }}$ was investigated using $\mathrm{SOC} / \mathrm{OC}$ ratio as the indicator rather than using SOC alone. The advantage of using SOC/OC is that the SOC variations induced by the non-secondary-formation process (e.g., PBLH shallowing) can be minimized, thereby focusing the analysis on the effect of secondary formation processes. A good diurnal correlation between SOC/OC and $E_{\text {abs520 }}$ was observed in the dry season $\left(R^{2}=0.53\right)$, but no correlation was found in the wet season $\left(R^{2}=0.01\right)$. The $E_{\text {abs }}$ dependence on SOC/OC was examined in Fig. 6. $E_{\text {abs }}$ dependence on SOC/OC was found in both wet and dry seasons, but a clearer dependence was observed in the dry season. It should be noted that a good $E_{\text {abs }}$ dependence on SOC/OC observed in Fig. 6 does not necessarily lead to a good diurnal correlation between $E_{\text {abs }}$ and SOC/OC (e.g., Fig. 4a). In other words, the dependency of $E_{\text {abs }}$ on SOC/OC might not necessarily be reflected in the form of correlation on a diurnal scale. Thus, the poor diurnal correlation between SOC/OC and $E_{\text {abs520 }}$ observed in the wet season (Fig. 4a) cannot rule out the contribution of SOC to $E_{\text {abs520. A study }}$ in Paris (Zhang et al., 2018a) found that more oxidized oxygenated organic aerosols (MO-OOA) and less oxidized OOA (LO-OOA), which are surrogates of SOA, were the dominating contributors for $E_{\mathrm{abs}}$, especially in the summertime. In the present study, due to the lack of quantitative chemical speciation data, quantification of contributions from different chemical species to $E_{\text {abs }}$ is not possible. A recent study in Guangzhou (Wu et al., 2019) found that traffic-derived SOC could be a significant source of SOC in the urban area, which can account for half of the total SOC. In that sense, traffic
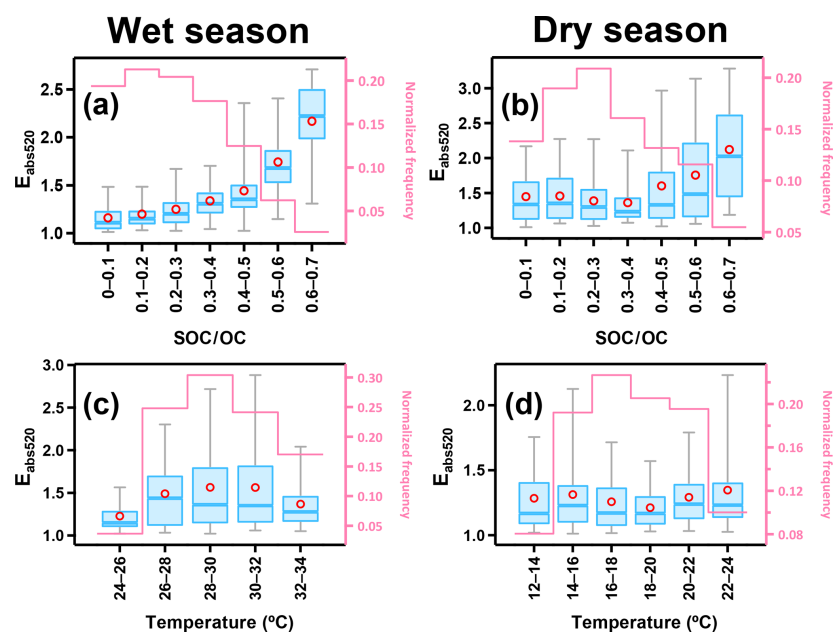

Figure 6. $E_{\mathrm{abs} 520}$ dependency on SOC/OC ratio and temperature during wet and dry seasons. Red circles represent the average values. The line inside the box indicates the median. Upper and lower boundaries of the box represent the 75th and the 25th percentiles; the whiskers above and below each box represent the 95th and 5th percentiles. The pink lines represent normalized frequency of data points in each bin.

emissions are expected to have a considerable contribution to $\mathrm{BC}$ light absorption enhancement in both wet and dry seasons.

The temperature effect on $E_{\text {abs }}$ was examined in Fig. $6 \mathrm{c}$ and $\mathrm{d}$ for wet and dry seasons, respectively. In the wet season, a positive response of $E_{\text {abs }}$ on temperature was observed for the temperature range of $24-30^{\circ} \mathrm{C}$, implying a favorable condition for coating formation on $\mathrm{BC}$ particles. However, further temperature increment beyond $30^{\circ} \mathrm{C}$ led to a decline of $E_{\mathrm{abs}}$, which might be associated with the evaporation of the coating materials on BC. In the dry season, $E_{\mathrm{abs}}$ was not sensitive to temperature for the range of $12-24^{\circ} \mathrm{C}$. The volatility effect of coating materials on $E_{\text {abs }}$ will be discussed in more detail in the next section.

\subsection{The influence of semivolatile compounds on $E_{\text {abs }}$ diurnal variations}

The SPAMS data from both wet (11-18 August 2017) and dry seasons (15 November to 27 December 2017) were analyzed to explore the mixing state of EC-containing particles from a single-particle perspective. The average EC-fresh and EC-aged mass spectra are shown in Fig. S13 for both wet and dry seasons. The domination of EC-aged particles in EC-containing particle number fraction suggests that most of the EC particles are internally mixed with other species (Table S3). This result agrees with previous studies in this region (Zhang et al., 2013, 2014).

To study the relative abundance of coating materials on EC particles, we investigate the ratios of RPA by different species (organics, sulfate and nitrate) to RPA by EC 

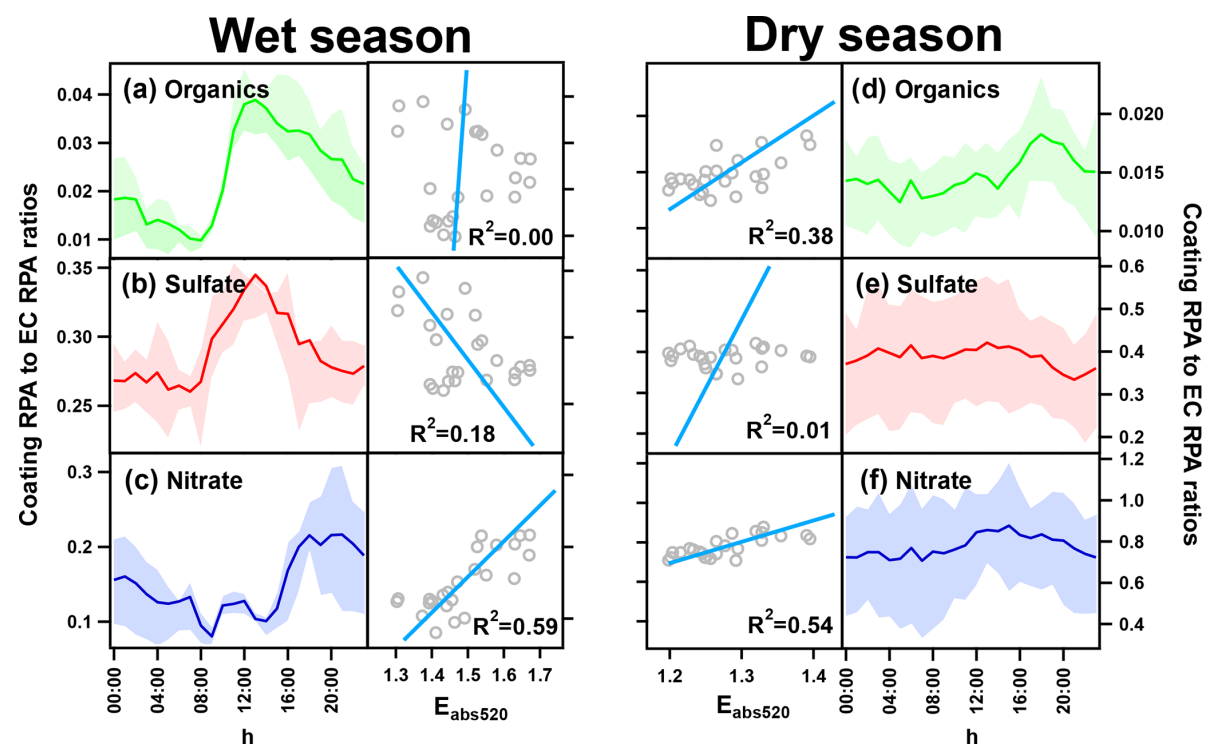

Figure 7. Diurnal variations in coating (including organics, sulfate and nitrate) RPA to EC RPA ratios of EC-aged particles measured by SPAMS in the wet and dry seasons. The solid lines represent hourly averages and the shaded areas represent 25 th and 75 th percentiles. (a-c) In the wet season, organics, nitrate and sulfate RPA to EC RPA ratios. The scatter plots show the corresponding correlations with

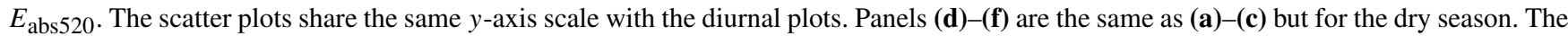
following ions are used: $\mathrm{EC}\left(m / z+12[\mathrm{C}]^{+},+24\left[\mathrm{C}_{2}\right]^{+},+36\left[\mathrm{C}_{3}\right]^{+},+48\left[\mathrm{C}_{4}\right]^{+}\right)$, organics $\left(m / z+43\left[\mathrm{C}_{2} \mathrm{H}_{3} \mathrm{O}\right]^{+}\right)$, sulfate $\left(m / z-97\left[\mathrm{HSO}_{4}\right]^{-}\right.$, $\left.-80\left[\mathrm{SO}_{3}\right]^{-}\right)$and nitrate $\left(\mathrm{m} / z-62\left[\mathrm{NO}_{3}\right]^{-},-46\left[\mathrm{NO}_{2}\right]^{-}\right)$.

in both wet and dry seasons (Fig. 7). In the wet season, the effect of organics and sulfate on EC-containing particles demonstrated similar diurnal trends that both peaked at 13:00, implying an association with photochemical reactions. The timing of the organic peak by SPAMS shown in Fig. 7a also agrees well with the bulk measurements of SOC/OC (Fig. 4a). However, the diurnal variations in organics and sulfate were poorly correlated with $E_{\text {abs520 }}$ as shown by the low $R^{2}$ in the scatter plot in Fig. 7a and b. There are two possibilities for the lower $R^{2}$ (organics, $E_{\text {abs }}$ ) in Fig. 7d compared to $R^{2}$ (SOC/OC, $E_{\text {abs }}$ ) in Fig. $4 \mathrm{~b}$. First, organics shown in Fig. 7d contain both primary and secondary organics, while SOC/OC ratio shown in Fig. 4b represents the secondary portion only. Second, poor diurnal correlations do not necessarily rule out the contribution of organics and sulfate to $E_{\text {abs }}$ by analogy with the SOC correlation with $E_{\text {abs }}$ as discussed in Sect. 3.6. Although the quantitative contribution estimation of sulfate and SOA to $E_{\mathrm{abs}}$ is not possible in this study, a rough estimation can be projected. Considering the typical annual average SOC concentration $\left(3 \mu \mathrm{gC} \mathrm{m}{ }^{-3}\right)$ (Wu et al., 2019), typical SOA/SOC mass ratio (1.8) (Li et al., 2017) and sulfate concentration $\left(8 \mu \mathrm{g} \mathrm{m}^{-3}\right)$ (J. Liu et al., 2017 ) in the PRD region, SOA and sulfate would likely have comparable contributions to the $E_{\text {abs }}$, according to the $E_{\text {abs }}$ dependency on sulfate-to-SOA mass ratio results by Zhang et al. (2018a). Summertime nitrate was low in daytime and high in the nighttime (Fig. 7c), which agrees with measurements at the roadside site in Hong Kong (Lee et al., 2015) and Shanghai (K. Li et al., 2018). Temperature-dependent gas-particle partitioning would be one of the possible reasons for the observed nitrate diurnal pattern (Appel et al., 1981; Xue et al., 2014; Griffith et al., 2015). A higher temperature during the daytime (Fig. S14) favors $\mathrm{HNO}_{3}$ partitioning into the gas-phase in the wet season. The diurnal pattern of nitrate correlates well with that of $E_{\text {abs520 }}\left(R^{2}=0.59\right)$ as shown in Fig. 7c, suggesting that $E_{\text {abs520 }}$ was likely affected by temperature-induced gas-particle partitioning during the wet season. Studies in Nanjing (Ma et al., 2020) and Beijing (Xie et al., 2019) also observed a nitrate-evaporation-induced $E_{\text {abs }}$ decrease, which is in agreement with our study. A previous chamber study has shown a decrease in $E_{\text {abs }}$ due to SOA evaporation (Metcalf et al., 2013). By analogy with nitrate, organic compounds with volatilities similar to nitrate might potentially be involved in shaping the diurnal pattern of $E_{\mathrm{abs}}$ in the wet season.

In the dry season, organics were moderately correlated with $E_{\text {abs520 }}\left(R^{2}=0.38\right)$ as shown in Fig. $7 \mathrm{~d}$. The improved correlation of organics in the dry season was in agreement with $\mathrm{O}_{x}$ and SOC/OC results as shown in Fig. 4b. Sulfate was still poorly correlated with $E_{\text {abs520 }}$. Since the contribution of sulfate on $E_{\text {abs } 520}$ cannot be ruled out, one possible explanation is that the contribution of sulfate on $E_{\text {abs520 }}$ was not reflected on the diurnal timescale. 


\section{Conclusions and implications}

This study explored the temporal dynamics of the optical properties of carbonaceous aerosols in urban Guangzhou, a typical megacity in southern China, focusing on the atmospheric aging-induced light absorption enhancement of BC. Field measurements were conducted at an urban site during the wet season (31 July-10 September 2017) and dry season (15 November 2017-15 January 2018). A newly developed approach, the minimum $R$ squared (MRS) method (Wu et al., 2018), was successfully applied to determine the light absorption enhancement factor, $E_{\text {abs }}$, using data from an Aethalometer and a field-deployable semicontinuous carbon analyzer. The MRS approach avoids a specialized instrument setup (e.g., thermal denuder and photo-acoustic spectrometer) for $E_{\text {abs }}$ determination, hence it has a great potential for expending the data pool of $E_{\mathrm{abs}}$, considering the fact that colocated Aethalometer and field carbon analyzer measurements have been widely deployed around the world.

Strong seasonality of BC was observed. The average concentration of EC was $1.94 \pm 0.93$ and $2.81 \pm 2.01 \mu \mathrm{gC} \mathrm{m}^{-3}$ in the wet and dry seasons, respectively. Collective evidence from remote sensing fire counts and ground measurements of levoglucosan showed that biomass burning (BB) was more active in the dry season. Consequently, optical properties of $\mathrm{BC}$ were effectively altered, leading to elevated MAE (dry season: $18.47 \pm 5.49 \mathrm{~m}^{2} \mathrm{~g}^{-1}$, wet season: $10.73 \pm 4.96 \mathrm{~m}^{2} \mathrm{~g}^{-1}$ ), MAE $\mathrm{p}$ (dry season: $15.8 \mathrm{~m}^{2} \mathrm{~g}^{-1}$, wet season: $8.1 \mathrm{~m}^{2} \mathrm{~g}^{-1}$ ) and AAE (dry season: $1.46 \pm 0.12$, wet season: $1.37 \pm 0.10$ ) in dry season compared to those in the wet season. However, little dependence of $E_{\mathrm{abs}}$ on wavelength was observed in the dry season despite the influence of BB.

The diurnal correlation analysis between AAE, $k$ and $E_{\text {abs }}$ revealed different results between wet and dry seasons. During the wet season when the BB influence was small, AAE was well correlated with $E_{\text {abs }}$, implying that the coating was likely the main driver for $\mathrm{AAE}>1$. In other words, the two-component AAE model might not be suitable for $\mathrm{BrC}$ absorption estimation under such circumstances. The Aethalometer loading effect correction factor, $k$, was confirmed to be a useful $E_{\text {abs }}$ indicator owing to its good correlation with $E_{\text {abs }}$ during the wet season. In the dry season, the weak correlation between $\mathrm{AAE}$ and $E_{\text {abs }}$ implies the contribution from $\mathrm{BB}$ to AAE. In the dry season, the BB influence leads to poor correlation between $k$ and $E_{\text {abs }}$, confirming that $k$ can only be used as the coating indicator when BB influence is small.
The effect of atmospheric aging on the $E_{\mathrm{abs}}$ diurnal pattern was examined. $\mathrm{O}_{x}$ and SOC/OC were found to be well correlated with $E_{\text {abs }}$ during the dry season, but no correlation was observed in the wet season. However, further analysis showed an $E_{\text {abs }}$ dependence on SOC/OC in both wet and dry seasons. This observation implies that a poor diurnal correlation in the wet season does not necessarily rule out the $E_{\text {abs }}$ contribution from SOC. In other words, the SOC contribution to $E_{\text {abs }}$ in the wet season was not necessarily reflected in just the diurnal correlation.

In the wet season, a high-temperature-induced $\left(>32^{\circ} \mathrm{C}\right)$ $E_{\text {abs }}$ decline was observed. In addition, a good diurnal correlation between nitrate and $E_{\mathrm{abs}}$ was found. These pieces of evidence imply the potential role of semivolatile coatings on $\mathrm{BC}$ in regulating the diurnal dynamics of $E_{\mathrm{abs}}$. In China, the sulfate problem has been effectively mitigated by the reduction measures implemented in recent years (Xia et al., 2016; Wang et al., 2017b). In contrast, nitrate increased substantially in recent years (Xu et al., 2019; M. Tian et al., 2019; H. Li et al., 2019; Wang et al., 2019). If the nitrate fraction in the coating materials on $\mathrm{BC}$ increases, the diurnal pattern of $E_{\mathrm{abs}}$ for BC may be affected by the fluctuation of nitrate content in aerosol particles. As a result, the increasing concentration of nitrate might potentially affect radiative forcing by $\mathrm{BC}$ in China. 


\section{Appendix A: Abbreviations}

\begin{tabular}{|c|c|}
\hline Abbreviation & Definition \\
\hline $\mathrm{AAE}_{470-660}$ & Ångström absorption exponent between 470 and $660 \mathrm{~nm}$ \\
\hline AFD & aerosol filter filtration-dissolution \\
\hline Aeth & Aethalometer \\
\hline ATN & attenuation \\
\hline BB & biomass burning \\
\hline $\mathrm{BC}$ & black carbon \\
\hline $\mathrm{BrC}$ & brown carbon \\
\hline$E_{\text {abs } 520}$ & light absorption enhancement factor at $520 \mathrm{~nm}$ \\
\hline$\sigma_{\text {abs } 520}$ & light absorption coefficient at $520 \mathrm{~nm}$ \\
\hline$\sigma_{\text {abs_total }}$ & total light absorption coefficient of a coated particle \\
\hline$\sigma_{\text {abs_pri }}$ & primary light absorption coefficient attributed to the soot core alone of a coated particle \\
\hline$\sigma_{\text {abs_aging }}$ & $\begin{array}{l}\text { extra light absorption other than } \sigma_{\text {abs_pri }} \text { (including those from the lensing effect that arises from a } \\
\text { non-absorbing coating on the soot core and secondary brown carbon during atmospheric aging) }\end{array}$ \\
\hline $\mathrm{eBC}$ & equivalent BC mass concentration determined by optical methods (e.g., Aethalometer) \\
\hline $\mathrm{EC}$ & elemental carbon \\
\hline GDEMC & Guangdong Environmental Monitoring Center \\
\hline GMB & Guangzhou Meteorological Bureau \\
\hline$k_{1}, k_{2} \ldots k_{7}$ & compensation factors (Eqs. 5 and 6 ) at seven wavelengths $(370,470,520,590,660,880$ and $950 \mathrm{~nm})$ \\
\hline LO-OOA & less oxidized oxygenated organic aerosol \\
\hline $\mathrm{MAE}_{520}$ & mass absorption efficiency at $520 \mathrm{~nm}$, also known as mass absorption cross-section (MAC) \\
\hline $\mathrm{MAE}_{\mathrm{p}}$ & primary MAE of freshly emitted soot particles \\
\hline $\mathrm{MAE}_{\mathrm{p} h}$ & a series of hypothetical MAE tested in the MRS calculation \\
\hline MAE + empirical & MAE approach for $E_{\text {abs }}$ quantification using empirical $\mathrm{MAE}_{\mathrm{p}}$ \\
\hline $\mathrm{MAE}+\mathrm{SP}$ & MAE approach for $E_{\mathrm{abs}}$ quantification using single-particle measurements for $\mathrm{MAE}_{\mathrm{p}}$ determination \\
\hline $\mathrm{MAE}+\mathrm{MRS}$ & MAE approach for $E_{\text {abs }}$ quantification using MRS for $\mathrm{MAE}_{\mathrm{p}}$ determination \\
\hline MO-OOA & more oxidized oxygenated organic aerosol \\
\hline MRS & minimum $R$ squared method \\
\hline $\mathrm{OC}$ & organic carbon \\
\hline OOA & oxygenated organic aerosol \\
\hline PAS & photoacoustic spectrometer \\
\hline PBL & planetary boundary layer \\
\hline PBLH & planetary boundary layer height \\
\hline POC & primary organic carbon \\
\hline PRD & Pearl River Delta region, China \\
\hline $\mathrm{rBC}$ & refectory black carbon (commonly used for reporting BC detected by SP2) \\
\hline$r_{\text {aged }}$ & the ratio of aged particles to fresh particles determined by SP2 \\
\hline RPA & relative peak area \\
\hline SOA & secondary organic aerosol \\
\hline SP2 & single-particle soot photometer \\
\hline SPAMS & single-particle aerosol mass spectrometer \\
\hline SP-AMS & soot particle aerosol mass spectrometer \\
\hline SSA & single-scattering albedo \\
\hline Suomi NPP & Suomi National Polar-orbiting Partnership \\
\hline TD & thermal denuder \\
\hline VIIRS & Visible Infrared Imaging Radiometer Suite \\
\hline VOCs & volatile organic compounds \\
\hline WODR & weighted orthogonal distance regression \\
\hline
\end{tabular}


Code and data availability. OC, EC and $\sigma_{\mathrm{abs}}$ data used in this study are available from the corresponding authors upon request. Data analysis and visualization toolkits (Histbox, MRS and Scatter Plot) used in this study are available at https://doi.org/10.5281/zenodo.832405 (Wu, 2020a), https://doi.org/10.5281/zenodo.832395 (Wu, 2020b) and https://doi.org/10.5281/zenodo.832416 (Wu, 2020c), respectively.

Supplement. The supplement related to this article is available online at: https://doi.org/10.5194/acp-20-2445-2020-supplement.

Author contributions. CW designed the study. JYS and CW performed the experiments. JYS, CW, CC, QZ and YL conducted the data analysis. JYS and CW wrote the paper with the inputs from all authors.

Competing interests. Yanxiang Cen and Huiqing Nian both work for Guangzhou Hexin Analytical Instrument Co., Ltd.

Acknowledgements. The authors gratefully acknowledge the NOAA Air Resources Laboratory (ARL) for the provision of the HYSPLIT transport and dispersion model used in this publication. We acknowledge the use of data from the NASA FIRMS application (https://firms.modaps.eosdis.nasa.gov/, last access: 26 February 2020) operated by the NASA/Goddard Space Flight Center Earth Science Data and Information System (ESDIS) project.

Financial support. This research has been supported by the National Key Research and Development Program of China (grant no. 2016YFC0208503), the National Natural Science Foundation of China (grant nos. 41605002 and 41475004), the Guangzhou Science and Technology Project (grant no. 201604016053), the Major Project of Industry-University-Research Collaborative Innovation in Guangzhou (grant no. 2016201604030082), and the Pearl River Nova Program of Guangzhou (grant no. 201610010149).

Review statement. This paper was edited by Annele Virtanen and reviewed by two anonymous referees.

\section{References}

Adler, G., Riziq, A. A., Erlick, C., and Rudich, Y.: Effect of intrinsic organic carbon on the optical properties of fresh diesel soot, P. Natl. Acad. Sci. USA, 107, 6699-6704, https://doi.org/10.1073/pnas.0903311106, 2010.

Adler, G., Flores, J. M., Abo Riziq, A., Borrmann, S., and Rudich, Y.: Chemical, physical, and optical evolution of biomass burning aerosols: a case study, Atmos. Chem. Phys., 11, 1491-1503, https://doi.org/10.5194/acp-11-1491-2011, 2011.
Albrecht, B. A.: Aerosols, Cloud Microphysics, and Fractional Cloudiness, Science, 245, 1227-1230, https://doi.org/10.1126/science.245.4923.1227, 1989.

Anderson, T. L., Charlson, R. J., Schwartz, S. E., Knutti, R., Boucher, O., Rodhe, H., and Heintzenberg, J.: Climate forcing by aerosols - a hazy picture, Science, 300, 1103-1104, https://doi.org/10.1126/science.1084777, 2003.

Appel, B. R., Tokiwa, Y., and Haik, M.: Sampling of nitrates in ambient air, Atmos. Environ., 15, 283-289, https://doi.org/10.1016/0004-6981(81)90029-9, 1981.

Apte, J. S., Marshall, J. D., Cohen, A. J., and Brauer, M.: Addressing Global Mortality from Ambient $\mathrm{PM}_{2.5}$, Environ. Sci. Technol., 49, 8057-8066, https://doi.org/10.1021/acs.est.5b01236, 2015.

Bai, Z., Cui, X., Wang, X., Xie, H., and Chen, B.: Light absorption of black carbon is doubled at Mt. Tai and typical urban area in North China, Sci. Total Environ., 635, 1144-1151, https://doi.org/10.1016/j.scitotenv.2018.04.244, 2018.

Bambha, R. P., Dansson, M. A., Schrader, P. E., and Michelsen, H. A.: Effects of volatile coatings and coating removal mechanisms on the morphology of graphitic soot, Carbon, 61, 80-96, https://doi.org/10.1016/j.carbon.2013.04.070, 2013.

Bhattarai, C., Samburova, V., Sengupta, D., Iaukea-Lum, M., Watts, A. C., Moosmüller, H., and Khlystov, A. Y.: Physical and chemical characterization of aerosol in fresh and aged emissions from open combustion of biomass fuels, Aerosol. Sci. Tech., 52, 12661282, https://doi.org/10.1080/02786826.2018.1498585, 2018.

Bhattarai, H., Saikawa, E., Wan, X., Zhu, H., Ram, K., Gao, S., Kang, S., Zhang, Q., Zhang, Y., Wu, G., Wang, X., Kawamura, K., Fu, P., and Cong, Z.: Levoglucosan as a tracer of biomass burning: Recent progress and perspectives, Atmos. Res., 220, 20-33, https://doi.org/10.1016/j.atmosres.2019.01.004, 2019.

Bian, Q., Alharbi, B., Shareef, M. M., Husain, T., Pasha, M. J., Atwood, S. A., and Kreidenweis, S. M.: Sources of $\mathrm{PM}_{2.5}$ carbonaceous aerosol in Riyadh, Saudi Arabia, Atmos. Chem. Phys., 18, 3969-3985, https://doi.org/10.5194/acp-18-3969-2018, 2018.

Bond, T. C. and Bergstrom, R. W.: Light absorption by carbonaceous particles: An investigative review, Aerosol. Sci. Tech., 40, 27-67, https://doi.org/10.1080/02786820500421521, 2006.

Bond, T. C., Habib, G., and Bergstrom, R. W.: Limitations in the enhancement of visible light absorption due to mixing state, J. Geophys. Res., 111, D20211, https://doi.org/10.1029/2006JD007315, 2006.

Bond, T. C., Doherty, S. J., Fahey, D. W., Forster, P. M., Berntsen, T., DeAngelo, B. J., Flanner, M. G., Ghan, S., Karcher, B., Koch, D., Kinne, S., Kondo, Y., Quinn, P. K., Sarofim, M. C., Schultz, M. G., Schulz, M., Venkataraman, C., Zhang, H., Zhang, S., Bellouin, N., Guttikunda, S. K., Hopke, P. K., Jacobson, M. Z., Kaiser, J. W., Klimont, Z., Lohmann, U., Schwarz, J. P., Shindell, D., Storelvmo, T., Warren, S. G., and Zender, C. S.: Bounding the role of black carbon in the climate system: A scientific assessment, J. Geophys. Res., 118, 5380-5552, https://doi.org/10.1002/jgrd.50171, 2013.

Bones, D. L., Henricksen, D. K., Mang, S. A., Gonsior, M., Bateman, A. P., Nguyen, T. B., Cooper, W. J., and Nizkorodov, S. A.: Appearance of strong absorbers and fluorophores in limonene$\mathrm{O}_{3}$ secondary organic aerosol due to $\mathrm{NH}_{4}^{+}$-mediated chemical aging over long time scales, J. Geophys. Res., 115, D05203, https://doi.org/10.1029/2009jd012864, 2010. 
Browne, E. C., Zhang, X., Franklin, J. P., Ridley, K. J., Kirchstetter, T. W., Wilson, K. R., Cappa, C. D., and Kroll, J. H.: Effect of heterogeneous oxidative aging on light absorption by biomass burning organic aerosol, Aerosol. Sci. Tech., 53, 66300674, https://doi.org/10.1080/02786826.2019.1599321, 2019.

Burtscher, H., Baltensperger, U., Bukowiecki, N., Cohn, P., Hüglin, C., Mohr, M., Matter, U., Nyeki, S., Schmatloch, V., Streit, N., and Weingartner, E.: Separation of volatile and nonvolatile aerosol fractions by thermodesorption: instrumental development and applications, J. Aerosol. Sci., 32, 427-442, https://doi.org/10.1016/S0021-8502(00)00089-6, 2001.

Cai, J., Zeng, X., Zhi, G., Gligorovski, S., Sheng, G., Yu, Z., Wang, X., and Peng, P.: Molecular Composition and Photochemical Evolution of Water Soluble Organic Carbon (WSOC) Extracted from Field Biomass Burning Aerosols using High Resolution Mass Spectrometry, Atmos. Chem. Phys. Discuss., https://doi.org/10.5194/acp-2019-608, in review, 2019.

Canonaco, F., Slowik, J. G., Baltensperger, U., and Prévôt, A. S. H.: Seasonal differences in oxygenated organic aerosol composition: implications for emissions sources and factor analysis, Atmos. Chem. Phys., 15, 6993-7002, https://doi.org/10.5194/acp15-6993-2015, 2015.

Cappa, C. D., Onasch, T. B., Massoli, P., Worsnop, D. R., Bates, T. S., Cross, E. S., Davidovits, P., Hakala, J., Hayden, K. L., Jobson, B. T., Kolesar, K. R., Lack, D. A., Lerner, B. M., Li, S.-M., Mellon, D., Nuaaman, I., Olfert, J. S., Petäjä, T., Quinn, P. K., Song, C., Subramanian, R., Williams, E. J., and Zaveri, R. A.: Radiative Absorption Enhancements Due to the Mixing State of Atmospheric Black Carbon, Science, 337, 1078-1081, https://doi.org/10.1126/science.1223447, 2012.

Cappa, C. D., Zhang, X., Russell, L. M., Collier, S., Lee, A. K. Y., Chen, C.-L., Betha, R., Chen, S., Liu, J., Price, D. J., Sanchez, K. J., McMeeking, G. R., Williams, L. R., Onasch, T. B., Worsnop, D. R., Abbatt, J., and Zhang, Q.: Light absorption by ambient black and brown carbon and its dependence on black carbon coating state for two California, USA cities in winter and summer, J. Geophys. Res., 124, 1550-1577, https://doi.org/10.1029/2018JD029501, 2019.

Chen, B., Bai, Z., Cui, X., Chen, J., Andersson, A., and Gustafsson, Ö.: Light absorption enhancement of black carbon from urban haze in Northern China winter, Environ. Pollut., 221, 418-426, https://doi.org/10.1016/j.envpol.2016.12.004, 2017.

Chen, H., Hu, D., Wang, L., Mellouki, A., and Chen, J.: Modification in light absorption cross section of laboratorygenerated black carbon-brown carbon particles upon surface reaction and hydration, Atmos. Environ., 116, 253-261, https://doi.org/10.1016/j.atmosenv.2015.06.052, 2015.

Cheng, Y., Engling, G., Moosmüller, H., Arnott, W. P., Chen, L. W. A., Wold, C. E., Hao, W. M., and He, K.-B.: Light absorption by biomass burning source emissions, Atmos. Environ., 127, 347354, https://doi.org/10.1016/j.atmosenv.2015.12.045, 2016.

Chung, S. H. and Seinfeld, J. H.: Global distribution and climate forcing of carbonaceous aerosols, J. Geophys. Res., 107, AAC 14-1-AAC 14-33, https://doi.org/10.1029/2001JD001397, 2002.

Conrad, B. M. and Johnson, M. R.: Mass absorption crosssection of flare-generated black carbon: Variability, predictive model, and implications, Carbon, 149, 760-771, https://doi.org/10.1016/j.carbon.2019.04.086, 2019.
Csiszar, I., Schroeder, W., Giglio, L., Ellicott, E., Vadrevu, K. P., Justice, C. O., and Wind, B.: Active fires from the Suomi NPP Visible Infrared Imaging Radiometer Suite: Product status and first evaluation results, J. Geophys. Res., 119, 803-816, https://doi.org/10.1002/2013jd020453, 2014.

Cui, F., Chen, M., Ma, Y., Zheng, J., Zhou, Y., Li, S., Qi, L., and Wang, L.: An intensive study on aerosol optical properties and affecting factors in Nanjing, China, J. Environ. Sci., 40, 35-43, https://doi.org/10.1016/j.jes.2015.08.017, 2016.

Cui, X., Wang, X., Yang, L., Chen, B., Chen, J., Andersson, A., and Gustafsson, Ö.: Radiative absorption enhancement from coatings on black carbon aerosols, Sci. Total Environ., 551, 51-56, https://doi.org/10.1016/j.scitotenv.2016.02.026, 2016.

Dasari, S., Andersson, A., Bikkina, S., Holmstrand, H., Budhavant, K., Satheesh, S., Asmi, E., Kesti, J., Backman, J., Salam, A., Bisht, D. S., Tiwari, S., Hameed, Z., and Gustafsson, Ö.: Photochemical degradation affects the light absorption of watersoluble brown carbon in the South Asian outflow, Sci. Adv., 5, eaau8066, https://doi.org/10.1126/sciadv.aau8066, 2019.

Dastanpour, R., Momenimovahed, A., Thomson, K., Olfert, J., and Rogak, S.: Variation of the optical properties of soot as a function of particle mass, Carbon, 124, 201-211, https://doi.org/10.1016/j.carbon.2017.07.005, 2017.

Deng, T., Deng, X., Li, F., Wang, S., and Wang, G.: Study on aerosol optical properties and radiative effect in cloudy weather in the Guangzhou region, Sci. Total Environ., 568, 147-154, https://doi.org/10.1016/j.scitotenv.2016.05.156, 2016.

Ding, A. J., Huang, X., Nie, W., Sun, J. N., Kerminen, V. M., Petäjä, T., Su, H., Cheng, Y. F., Yang, X. Q., Wang, M. H., Chi, X. G., Wang, J. P., Virkkula, A., Guo, W. D., Yuan, J., Wang, S. Y., Zhang, R. J., Wu, Y. F., Song, Y., Zhu, T., Zilitinkevich, S., Kulmala, M., and Fu, C. B.: Enhanced haze pollution by black carbon in megacities in China, Geophys. Res. Lett., 43, 2873-2879, https://doi.org/10.1002/2016GL067745, 2016.

Ditas, J., Ma, N., Zhang, Y., Assmann, D., Neumaier, M., Riede, H., Karu, E., Williams, J., Scharffe, D., Wang, Q., Saturno, J., Schwarz, J. P., Katich, J. M., McMeeking, G. R., Zahn, A., Hermann, M., Brenninkmeijer, C. A. M., Andreae, M. O., Pöschl, U., Su, H., and Cheng, Y.: Strong impact of wildfires on the abundance and aging of black carbon in the lowermost stratosphere, P. Natl. Acad. Sci. USA, 115, E11595-E11603, https://doi.org/10.1073/pnas.1806868115, 2018.

Draxier, R. R. and Hess, G. D.: An overview of the HYSPLIT_4 modelling system for trajectories, dispersion and deposition, Aust. Meteorol. Mag., 47, 295-308, 1998.

Drinovec, L., Močnik, G., Zotter, P., Prévôt, A. S. H., Ruckstuhl, C., Coz, E., Rupakheti, M., Sciare, J., Müller, T., Wiedensohler, A., and Hansen, A. D. A.: The "dual-spot" Aethalometer: an improved measurement of aerosol black carbon with realtime loading compensation, Atmos. Meas. Tech., 8, 1965-1979, https://doi.org/10.5194/amt-8-1965-2015, 2015.

Drinovec, L., Gregorič, A., Zotter, P., Wolf, R., Bruns, E. A., Prévôt, A. S. H., Petit, J.-E., Favez, O., Sciare, J., Arnold, I. J., Chakrabarty, R. K., Moosmüller, H., Filep, A., and Močnik, G.: The filter-loading effect by ambient aerosols in filter absorption photometers depends on the coating of the sampled particles, Atmos. Meas. Tech., 10, 1043-1059, https://doi.org/10.5194/amt10-1043-2017, 2017. 
Engling, G., Carrico, C. M., Kreidenweis, S. M., Collett Jr., J. L., Day, D. E., Malm, W. C., Lincoln, E., Min Hao, W., Inuma, Y., and Herrmann, H.: Determination of levoglucosan in biomass combustion aerosol by highperformance anion-exchange chromatography with pulsed amperometric detection, Atmos. Environ., 40, 299-311, https://doi.org/10.1016/j.atmosenv.2005.12.069, 2006.

Fan, X., Yu, X., Wang, Y., Xiao, X., Li, F., Xie, Y., Wei, S., Song, J., and Peng, P. A.: The aging behaviors of chromophoric biomass burning brown carbon during dark aqueous hydroxyl radical oxidation processes in laboratory studies, Atmos. Environ., 205, 918, https://doi.org/10.1016/j.atmosenv.2019.02.039, 2019.

Fang, Y., Chen, Y., Lin, T., Hu, L., Tian, C., Luo, Y., Yang, X., Li, J., and Zhang, G.: Spatiotemporal Trends of Elemental Carbon and Char/Soot Ratios in Five Sediment Cores from Eastern China Marginal Seas: Indicators of Anthropogenic Activities and Transport Patterns, Environ. Sci. Technol., 52, 9704-9712, https://doi.org/10.1021/acs.est.8b00033, 2018.

Fierce, L., Bond, T. C., Bauer, S. E., Mena, F., and Riemer, N.: Black carbon absorption at the global scale is affected by particle-scale diversity in composition, Nat. Commun., 7, 12361, https://doi.org/10.1038/ncomms12361, 2016.

Flanner, M. G., Zender, C. S., Randerson, J. T., and Rasch, P. J.: Present-day climate forcing and response from black carbon in snow, J. Geophys. Res., 112, D11202, https://doi.org/10.1029/2006JD008003, 2007.

Fortenberry, C. F., Walker, M. J., Zhang, Y., Mitroo, D., Brune, W. H., and Williams, B. J.: Bulk and molecular-level characterization of laboratory-aged biomass burning organic aerosol from oak leaf and heartwood fuels, Atmos. Chem. Phys., 18, 21992224, https://doi.org/10.5194/acp-18-2199-2018, 2018.

Fuller, K. A., Malm, W. C., and Kreidenweis, S. M.: Effects of mixing on extinction by carbonaceous particles, J. Geophys. Res., 104, 15941-15954, https://doi.org/10.1029/1998JD100069, 1999.

Gertler, C. G., Puppala, S. P., Panday, A., Stumm, D., and Shea, J.: Black carbon and the Himalayan cryosphere: A review, Atmos. Environ., 125, 404-417, https://doi.org/10.1016/j.atmosenv.2015.08.078, 2016.

Ghazi, R. and Olfert, J. S.: Coating Mass Dependence of Soot Aggregate Restructuring due to Coatings of Oleic Acid and Dioctyl Sebacate, Aerosol. Sci. Tech., 47, 192-200, https://doi.org/10.1080/02786826.2012.741273, 2013.

Gilardoni, S., Massoli, P., Paglione, M., Giulianelli, L., Carbone, C., Rinaldi, M., Decesari, S., Sandrini, S., Costabile, F., Gobbi, G. P., Pietrogrande, M. C., Visentin, M., Scotto, F., Fuzzi, S., and Facchini, M. C.: Direct observation of aqueous secondary organic aerosol from biomassburning emissions, P. Natl. Acad. Sci. USA, 113, 10013-10018, https://doi.org/10.1073/pnas.1602212113, 2016.

Grahame, T. J., Klemm, R., and Schlesinger, R. B.: Public health and components of particulate matter: The changing assessment of black carbon, J. Air Waste Manage., 64, 620-660, https://doi.org/10.1080/10962247.2014.912692, 2014.

Griffith, S. M., Huang, X. H. H., Louie, P. K. K., and Yu, J. Z.: Characterizing the thermodynamic and chemical composition factors controlling $\mathrm{PM}_{2.5}$ nitrate: Insights gained from two years of online measurements in Hong Kong, Atmos. Environ., 122, 864875, https://doi.org/10.1016/j.atmosenv.2015.02.009, 2015.
Gross, D. S., Gälli, M. E., Silva, P. J., and Prather, K. A.: Relative Sensitivity Factors for Alkali Metal and Ammonium Cations in Single-Particle Aerosol Time-of-Flight Mass Spectra, Anal. Chem., 72, 416-422, https://doi.org/10.1021/ac990434g, 2000.

Hallquist, M., Wenger, J. C., Baltensperger, U., Rudich, Y., Simpson, D., Claeys, M., Dommen, J., Donahue, N. M., George, C., Goldstein, A. H., Hamilton, J. F., Herrmann, H., Hoffmann, T., Iinuma, Y., Jang, M., Jenkin, M. E., Jimenez, J. L., Kiendler-Scharr, A., Maenhaut, W., McFiggans, G., Mentel, Th. F., Monod, A., Prévôt, A. S. H., Seinfeld, J. H., Surratt, J. D., Szmigielski, R., and Wildt, J.: The formation, properties and impact of secondary organic aerosol: current and emerging issues, Atmos. Chem. Phys., 9, 5155-5236, https://doi.org/10.5194/acp9-5155-2009, 2009.

Hansen, J. and Nazarenko, L.: Soot climate forcing via snow and ice albedos, P. Natl. Acad. Sci. USA, 101, 423-428, https://doi.org/10.1073/pnas.2237157100, 2004.

Hatch, L. E., Pratt, K. A., Huffman, J. A., Jimenez, J. L., and Prather, K. A.: Impacts of Aerosol Aging on Laser Desorption/Ionization in Single-Particle Mass Spectrometers, Aerosol. Sci. Tech., 48, 1050-1058, https://doi.org/10.1080/02786826.2014.955907, 2014.

He, C., Flanner, M. G., Chen, F., Barlage, M., Liou, K.-N., Kang, S., Ming, J., and Qian, Y.: Black carbon-induced snow albedo reduction over the Tibetan Plateau: uncertainties from snow grain shape and aerosol-snow mixing state based on an updated SNICAR model, Atmos. Chem. Phys., 18, 11507-11527, https://doi.org/10.5194/acp-18-11507-2018, 2018.

Healy, R. M., Wang, J. M., Jeong, C. H., Lee, A. K. Y., Willis, M. D., Jaroudi, E., Zimmerman, N., Hilker, N., Murphy, M., Eckhardt, S., Stohl, A., Abbatt, J. P. D., Wenger, J. C., and Evans, G. J.: Light-absorbing properties of ambient black carbon and brown carbon from fossil fuel and biomass burning sources, J. Geophys. Res., 120, 2015JD023382, https://doi.org/10.1002/2015JD023382, 2015.

Hems, R. F. and Abbatt, J. P. D.: Aqueous Phase Photooxidation of Brown Carbon Nitrophenols: Reaction Kinetics, Mechanism, and Evolution of Light Absorption, ACS Earth and Space Chemistry, 2, 225-234, https://doi.org/10.1021/acsearthspacechem.7b00123, 2018.

Huang, X. H. H., Bian, Q. J., Louie, P. K. K., and Yu, J. Z.: Contributions of vehicular carbonaceous aerosols to $\mathrm{PM}_{2.5}$ in a roadside environment in Hong Kong, Atmos. Chem. Phys., 14, 92799293, https://doi.org/10.5194/acp-14-9279-2014, 2014.

Huntzicker, J. J., Johnson, R. L., Shah, J. J., and Cary, R. A.: Analysis of Organic and Elemental Carbon in Ambient Aerosols by a Thermal-Optical Method, in: Particulate Carbon: Atmospheric Life Cycle, edited by: Wolff, G. T. and Klimisch, R. L., Springer US, Boston, MA, 79-88, 1982.

IPCC: Climate change 2013: the physical science basis: Working Group I contribution to the Fifth Assessment Report of the Intergovernmental Panel on Climate Change, xi, 1535 pp., 2013.

Irwin, M., Kondo, Y., Moteki, N., and Miyakawa, T.: Evaluation of a Heated-Inlet for Calibration of the SP2, Aerosol. Sci. Tech., 47, 895-905, https://doi.org/10.1080/02786826.2013.800187, 2013.

Jacobson, M. Z.: Isolating nitrated and aromatic aerosols and nitrated aromatic gases as sources of ultraviolet light absorption, J. Geophys. Res., 104, 3527-3542, https://doi.org/10.1029/1998jd100054, 1999. 
Jacobson, M. Z.: Strong radiative heating due to the mixing state of black carbon in atmospheric aerosols, Nature, 409, 695-697, https://doi.org/10.1038/35055518, 2001.

Jeong, C.-H., McGuire, M. L., Godri, K. J., Slowik, J. G., Rehbein, P. J. G., and Evans, G. J.: Quantification of aerosol chemical composition using continuous single particle measurements, Atmos. Chem. Phys., 11, 7027-7044, https://doi.org/10.5194/acp11-7027-2011, 2011.

Ji, D., Gao, M., Maenhaut, W., He, J., Wu, C., Cheng, L., Gao, W., Sun, Y., Sun, J., Xin, J., Wang, L., and Wang, Y.: The carbonaceous aerosol levels still remain a challenge in the BeijingTianjin-Hebei region of China: Insights from continuous high temporal resolution measurements in multiple cities, Environ. Int., 126, 171-183, https://doi.org/10.1016/j.envint.2019.02.034, 2019.

Ji, Y., Qin, X., Wang, B., Xu, J., Shen, J., Chen, J., Huang, K., Deng, C., Yan, R., Xu, K., and Zhang, T.: Counteractive effects of regional transport and emission control on the formation of fine particles: a case study during the Hangzhou G20 summit, Atmos. Chem. Phys., 18, 13581-13600, https://doi.org/10.5194/acp-1813581-2018, 2018.

Johansson, K. O., Head-Gordon, M. P., Schrader, P. E., Wilson, K. R., and Michelsen, H. A.: Resonancestabilized hydrocarbon-radical chain reactions may explain soot inception and growth, Science, 361, 997-1000, https://doi.org/10.1126/science.aat3417, 2018.

Jung, J., Kim, Y. J., Lee, K. Y., Kawamura, K., Hu, M., and Kondo, Y.: The effects of accumulated refractory particles and the peak inert mode temperature on semi-continuous organic carbon and elemental carbon measurements during the CAREBeijing 2006 campaign, Atmos. Environ., 45, 7192-7200, https://doi.org/10.1016/j.atmosenv.2011.09.003, 2011.

Kanakidou, M., Seinfeld, J. H., Pandis, S. N., Barnes, I., Dentener, F. J., Facchini, M. C., Van Dingenen, R., Ervens, B., Nenes, A., Nielsen, C. J., Swietlicki, E., Putaud, J. P., Balkanski, Y., Fuzzi, S., Horth, J., Moortgat, G. K., Winterhalter, R., Myhre, C. E. L., Tsigaridis, K., Vignati, E., Stephanou, E. G., and Wilson, J.: Organic aerosol and global climate modelling: a review, Atmos. Chem. Phys., 5, 1053-1123, https://doi.org/10.5194/acp-5-10532005, 2005.

Kaufman, Y. J. and Koren, I.: Smoke and pollution aerosol effect on cloud cover, Science, 313, 655-658, https://doi.org/10.1126/science.1126232, 2006.

Knox, A., Evans, G. J., Brook, J. R., Yao, X., Jeong, C. H., Godri, K. J., Sabaliauskas, K., and Slowik, J. G.: Mass Absorption Cross-Section of Ambient Black Carbon Aerosol in Relation to Chemical Age, Aerosol. Sci. Tech., 43, 522-532, https://doi.org/10.1080/02786820902777207, 2009.

Koch, D. and Del Genio, A. D.: Black carbon semi-direct effects on cloud cover: review and synthesis, Atmos. Chem. Phys., 10, 7685-7696, https://doi.org/10.5194/acp-10-7685-2010, 2010.

Kondo, Y., Matsui, H., Moteki, N., Sahu, L., Takegawa, N., Kajino, M., Zhao, Y., Cubison, M. J., Jimenez, J. L., Vay, S., Diskin, G. S., Anderson, B., Wisthaler, A., Mikoviny, T., Fuelberg, H. E., Blake, D. R., Huey, G., Weinheimer, A. J., Knapp, D. J., and Brune, W. H.: Emissions of black carbon, organic, and inorganic aerosols from biomass burning in North America and Asia in 2008, J. Geophys. Res., 116, D08204, https://doi.org/10.1029/2010jd015152, 2011.
Kopacz, M., Mauzerall, D. L., Wang, J., Leibensperger, E. M., Henze, D. K., and Singh, K.: Origin and radiative forcing of black carbon transported to the Himalayas and Tibetan Plateau, Atmos. Chem. Phys., 11, 2837-2852, https://doi.org/10.5194/acp-11-2837-2011, 2011.

Krasowsky, T. S., McMeeking, G. R., Wang, D., Sioutas, C., and Ban-Weiss, G. A.: Measurements of the impact of atmospheric aging on physical and optical properties of ambient black carbon particles in Los Angeles, Atmos. Environ., 142, 496-504, https://doi.org/10.1016/j.atmosenv.2016.08.010, 2016.

Kumar, N. K., Corbin, J. C., Bruns, E. A., Massabó, D., Slowik, J. G., Drinovec, L., Močnik, G., Prati, P., Vlachou, A., Baltensperger, U., Gysel, M., El-Haddad, I., and Prévôt, A. S. H.: Production of particulate brown carbon during atmospheric aging of residential wood-burning emissions, Atmos. Chem. Phys., 18, 17843-17861, https://doi.org/10.5194/acp-18-178432018, 2018.

Lack, D. A. and Cappa, C. D.: Impact of brown and clear carbon on light absorption enhancement, single scatter albedo and absorption wavelength dependence of black carbon, Atmos. Chem. Phys., 10, 4207-4220, https://doi.org/10.5194/acp10-4207-2010, 2010.

Lack, D. A. and Langridge, J. M.: On the attribution of black and brown carbon light absorption using the Ångström exponent, Atmos. Chem. Phys., 13, 10535-10543, https://doi.org/10.5194/acp-13-10535-2013, 2013.

Lack, D. A., Langridge, J. M., Bahreini, R., Cappa, C. D., Middlebrook, A. M., and Schwarz, J. P.: Brown carbon and internal mixing in biomass burning particles, P. Natl. Acad. Sci. USA, 109, 14802-14807, https://doi.org/10.1073/pnas.1206575109, 2012a.

Lack, D. A., Richardson, M. S., Law, D., Langridge, J. M., Cappa, C. D., McLaughlin, R. J., and Murphy, D. M.: Aircraft instrument for comprehensive characterization of aerosol optical properties, Part 2: black and brown carbon absorption and absorption enhancement measured with photo acoustic spectroscopy, Aerosol. Sci. Tech., 46, 555-568, https://doi.org/10.1080/02786826.2011.645955, 2012b.

Lambe, A. T., Cappa, C. D., Massoli, P., Onasch, T. B., Forestieri, S. D., Martin, A. T., Cummings, M. J., Croasdale, D. R., Brune, W. H., Worsnop, D. R., and Davidovits, P.: Relationship between Oxidation Level and Optical Properties of Secondary Organic Aerosol, Environ. Sci. Technol., 47, 6349-6357, https://doi.org/10.1021/es401043j, 2013.

Lan, Z.-J., Huang, X.-F., Yu, K.-Y., Sun, T.-L., Zeng, L.W., and $\mathrm{Hu}, \mathrm{M}$.: Light absorption of black carbon aerosol and its enhancement by mixing state in an urban atmosphere in South China, Atmos. Environ., 69, 118-123, https://doi.org/10.1016/j.atmosenv.2012.12.009, 2013.

Laskin, A., Laskin, J., and Nizkorodov, S. A.: Chemistry of Atmospheric Brown Carbon, Chem. Rev., 115, 4335-4382, https://doi.org/10.1021/cr5006167, 2015.

Lee, A. K. Y., Rivellini, L.-H., Chen, C.-L., Liu, J., Price, D., Betha, R., Russell, L. M., Zhang, X., and Cappa, C. D.: Influences of primary emission and secondary coating formation on the particle diversity and mixing state of black carbon particles, Environ. Sci. Technol., 53, 9429-9438, https://doi.org/10.1021/acs.est.9b03064, 2019.

Lee, B. P., Li, Y. J., Yu, J. Z., Louie, P. K. K., and Chan, C. K.: Characteristics of submicron particulate matter at the 
urban roadside in downtown Hong Kong - Overview of 4 months of continuous high-resolution aerosol mass spectrometer measurements, J. Geophys. Res., 120, 7040-7058, https://doi.org/10.1002/2015jd023311, 2015.

Lee, H. J., Aiona, P. K., Laskin, A., Laskin, J., and Nizkorodov, S. A.: Effect of Solar Radiation on the Optical Properties and Molecular Composition of Laboratory Proxies of Atmospheric Brown Carbon, Environ. Sci. Technol., 48, 1021710226, https://doi.org/10.1021/es502515r, 2014.

Lefevre, G., Yon, J., Bouvier, M., Liu, F., and Coppalle, A.: Impact of Organic Coating on Soot Angular and Spectral Scattering Properties, Environ. Sci. Technol., 53, 6383-6391, https://doi.org/10.1021/acs.est.8b05482, 2019.

Levin, E. J. T., McMeeking, G. R., Carrico, C. M., Mack, L. E., Kreidenweis, S. M., Wold, C. E., Moosmüller, H., Arnott, W. P., Hao, W. M., Collett Jr., J. L., and Malm, W. C.: Biomass burning smoke aerosol properties measured during Fire Laboratory at Missoula Experiments (FLAME), J. Geophys. Res., 115, D18210, https://doi.org/10.1029/2009jd013601, 2010.

Levy II, H., Mahlman, J. D., Moxim, W. J., and Liu, S. C.: Tropospheric ozone: The role of transport, J. Geophys. Res., 90, 37533772, https://doi.org/10.1029/JD090iD02p03753, 1985.

Lewis, K., Arnott, W. P., Moosmüller, H., and Wold, C. E.: Strong spectral variation of biomass smoke light absorption and single scattering albedo observed with a novel dual-wavelength photoacoustic instrument, J. Geophys. Res., 113, D16203, https://doi.org/10.1029/2007jd009699, 2008.

Li, C., He, Q., Schade, J., Passig, J., Zimmermann, R., Meidan, D., Laskin, A., and Rudich, Y.: Dynamic changes in optical and chemical properties of tar ball aerosols by atmospheric photochemical aging, Atmos. Chem. Phys., 19, 139-163, https://doi.org/10.5194/acp-19-139-2019, 2019.

Li, G.-L., Sun, L., Ho, K.-F., Wong, K.-C., and Ning, Z.: Implication of Light Absorption Enhancement and Mixing State of Black Carbon (BC) by Coatings in Hong Kong, Aerosol Air. Qual. Res., 18, 2753-2763, https://doi.org/10.4209/aaqr.2017.11.0473, 2018.

Li, H., Cheng, J., Zhang, Q., Zheng, B., Zhang, Y., Zheng, G., and $\mathrm{He}, \mathrm{K}$. : Rapid transition in winter aerosol composition in Beijing from 2014 to 2017: response to clean air actions, Atmos. Chem. Phys., 19, 11485-11499, https://doi.org/10.5194/acp-19-114852019, 2019.

Li, K., Ye, X., Pang, H., Lu, X., Chen, H., Wang, X., Yang, $\mathrm{X}$., Chen, J., and Chen, Y.: Temporal variations in the hygroscopicity and mixing state of black carbon aerosols in a polluted megacity area, Atmos. Chem. Phys., 18, 15201-15218, https://doi.org/10.5194/acp-18-15201-2018, 2018.

Li, L., Huang, Z., Dong, J., Li, M., Gao, W., Nian, H., Fu, Z., Zhang, G., Bi, X., Cheng, P., and Zhou, Z.: Real time bipolar time-of-flight mass spectrometer for analyzing single aerosol particles, Int. J. Mass Spectrom., 303, 118-124, https://doi.org/10.1016/j.ijms.2011.01.017, 2011.

Li, M., Bao, F., Zhang, Y., Song, W., Chen, C., and Zhao, J.: Role of elemental carbon in the photochemical aging of soot, P. Natl. Acad. Sci., 115, 7717-7722, https://doi.org/10.1073/pnas.1804481115, 2018.

Li, S., Zhu, M., Yang, W., Tang, M., Huang, X., Yu, Y., Fang, H., Yu, X., Yu, Q., Fu, X., Song, W., Zhang, Y., Bi, X., and Wang, X.: Filter-based measurement of light absorption by brown carbon in $\mathrm{PM}_{2.5}$ in a megacity in South China, Sci. Total Environ., 633, 1360-1369, https://doi.org/10.1016/j.scitotenv.2018.03.235, 2018.

Li, Y. J., Sun, Y., Zhang, Q., Li, X., Li, M., Zhou, Z., and Chan, C. K.: Real-time chemical characterization of atmospheric particulate matter in China: A review, Atmos. Environ., 158, 270-304, https://doi.org/10.1016/j.atmosenv.2017.02.027, 2017.

Li, Z., Tan, H., Zheng, J., Liu, L., Qin, Y., Wang, N., Li, F., Li, Y., Cai, M., Ma, Y., and Chan, C. K.: Light absorption properties and potential sources of particulate brown carbon in the Pearl River Delta region of China, Atmos. Chem. Phys., 19, 11669-11685, https://doi.org/10.5194/acp-19-11669-2019, 2019.

Liakakou, E., Kaskaoutis, D. G., Grivas, G., Stavroulas, I., Tsagkaraki, M., Paraskevopoulou, D., Bougiatioti, A., Dumka, U. C., Gerasopoulos, E., and Mihalopoulos, N.: Longterm brown carbon spectral characteristics in a Mediterranean city (Athens), Sci. Total Environ., 708, 135019, https://doi.org/10.1016/j.scitotenv.2019.135019, 2019.

Liang, C., Pankow, J. F., Odum, J. R., and Seinfeld, J. H.: Gas/Particle Partitioning of Semivolatile Organic Compounds To Model Inorganic, Organic, and Ambient Smog Aerosols, Environ. Sci. Technol., 31, 3086-3092, https://doi.org/10.1021/es9702529, 1997.

Lin, P., Laskin, J., Nizkorodov, S. A., and Laskin, A.: Revealing Brown Carbon Chromophores Produced in Reactions of Methylglyoxal with Ammonium Sulfate, Environ. Sci. Technol., 49, 14257-14266, https://doi.org/10.1021/acs.est.5b03608, 2015.

Lin, P., Aiona, P. K., Li, Y., Shiraiwa, M., Laskin, J., Nizkorodov, S. A., and Laskin, A.: Molecular Characterization of Brown Carbon in Biomass Burning Aerosol Particles, Environ. Sci. Technol., 50, 11815-11824, https://doi.org/10.1021/acs.est.6b03024, 2016.

Liu, B., Ma, Y., Gong, W., Zhang, M., and Shi, Y.: The relationship between black carbon and atmospheric boundary layer height, Atmos. Pollut. Res., 10, 65-72, https://doi.org/10.1016/j.apr.2018.06.007, 2019.

Liu, D., Allan, J. D., Young, D. E., Coe, H., Beddows, D., Fleming, Z. L., Flynn, M. J., Gallagher, M. W., Harrison, R. M., Lee, J., Prevot, A. S. H., Taylor, J. W., Yin, J., Williams, P. I., and Zotter, P.: Size distribution, mixing state and source apportionment of black carbon aerosol in London during wintertime, Atmos. Chem. Phys., 14, 10061-10084, https://doi.org/10.5194/acp-1410061-2014, 2014.

Liu, D., Whitehead, J., Alfarra, M. R., Reyes-Villegas, E., Spracklen, D. V., Reddington, C. L., Kong, S., Williams, P. I., Ting, Y.-C., Haslett, S., Taylor, J. W., Flynn, M. J., Morgan, W. T., McFiggans, G., Coe, H., and Allan, J. D.: Black-carbon absorption enhancement in the atmosphere determined by particle mixing state, Nat. Geosci., 10, 184-188, https://doi.org/10.1038/ngeo2901, 2017.

Liu, F., Yon, J., and Bescond, A.: On the radiative properties of soot aggregates - Part 2: Effects of coating, J. Quant. Spectrosc. Ra., 172, 134-145, https://doi.org/10.1016/j.jqsrt.2015.08.005, 2016.

Liu, H., Pan, X., Liu, D., Liu, X., Chen, X., Tian, Y., Sun, Y., Fu, P., and Wang, Z.: Mixing characteristics of refractory black carbon aerosols determined by a tandem CPMA-SP2 system at an urban site in Beijing, Atmos. Chem. Phys. Discuss., https://doi.org/10.5194/acp-2019-244, in review, 2019a. 
Liu, H., Pan, X., Wu, Y., Wang, D., Tian, Y., Liu, X., Lei, L., Sun, Y., Fu, P., and Wang, Z.: Effective densities of soot particles and their relationships with the mixing state at an urban site in the Beijing megacity in the winter of 2018, Atmos. Chem. Phys., 19, 1479114804, https://doi.org/10.5194/acp-19-14791-2019, 2019b.

Liu, J., Lin, P., Laskin, A., Laskin, J., Kathmann, S. M., Wise, M., Caylor, R., Imholt, F., Selimovic, V., and Shilling, J. E.: Optical properties and aging of light-absorbing secondary organic aerosol, Atmos. Chem. Phys., 16, 12815-12827, https://doi.org/10.5194/acp-16-12815-2016, 2016.

Liu, J., Wu, D., Fan, S., Mao, X., and Chen, H.: A one-year, on-line, multi-site observational study on watersoluble inorganic ions in $\mathrm{PM}_{2.5}$ over the Pearl River Delta region, China, Sci. Total Environ., 601-602, 1720-1732, https://doi.org/10.1016/j.scitotenv.2017.06.039, 2017.

Liu, S., Aiken, A. C., Gorkowski, K., Dubey, M. K., Cappa, C. D., Williams, L. R., Herndon, S. C., Massoli, P., Fortner, E. C., Chhabra, P. S., Brooks, W. A., Onasch, T. B., Jayne, J. T., Worsnop, D. R., China, S., Sharma, N., Mazzoleni, C., Xu, L., Ng, N. L., Liu, D., Allan, J. D., Lee, J. D., Fleming, Z. L., Mohr, C., Zotter, P., Szidat, S., and Prevot, A. S. H.: Enhanced light absorption by mixed source black and brown carbon particles in UK winter, Nat. Commun., 6, 8435, https://doi.org/10.1038/ncomms9435, 2015.

Liu, S. C.: Possible effects on fropospheric $\mathrm{O}_{3}$ and $\mathrm{OH}$ due to No emissions, Geophys. Res. Lett., 4, 325-328, https://doi.org/10.1029/GL004i008p00325, 1977.

Ma, X., Zangmeister, C. D., Gigault, J., Mulholland, G. W., and Zachariah, M. R.: Soot aggregate restructuring during water processing, J. Aerosol. Sci., 66, 209-219, https://doi.org/10.1016/j.jaerosci.2013.08.001, 2013.

Ma, Y., Huang, C., Jabbour, H., Zheng, Z., Wang, Y., Jiang, Y., Zhu, W., and Zheng, J.: Mixing state and light absorption enhancement of black carbon aerosols in summertime Nanjing, China, Atmos. Environ., 222, 117141, https://doi.org/10.1016/j.atmosenv.2019.117141, 2020.

Martinsson, J., Eriksson, A. C., Nielsen, I. E., Malmborg, V. B., Ahlberg, E., Andersen, C., Lindgren, R., Nyström, R., Nordin, E. Z., Brune, W. H., Svenningsson, B., Swietlicki, E., Boman, C., and Pagels, J. H.: Impacts of Combustion Conditions and Photochemical Processing on the Light Absorption of Biomass Combustion Aerosol, Environ. Sci. Technol., 49, 14663-14671, https://doi.org/10.1021/acs.est.5b03205, 2015.

Matsui, H., Hamilton, D. S., and Mahowald, N. M.: Black carbon radiative effects highly sensitive to emitted particle size when resolving mixing-state diversity, Nat. Commun., 9, 3446, https://doi.org/10.1038/s41467-018-05635-1, 2018.

McMeeking, G. R., Kreidenweis, S. M., Baker, S., Carrico, C. M., Chow, J. C., Collett, J. L., Hao, W. M., Holden, A. S., Kirchstetter, T. W., Malm, W. C., Moosmüller, H., Sullivan, A. P., and Wold, C. E.: Emissions of trace gases and aerosols during the open combustion of biomass in the laboratory, J. Geophys. Res., 114, D19210, https://doi.org/10.1029/2009JD011836, 2009.

McMeeking, G. R., Fortner, E., Onasch, T. B., Taylor, J. W., Flynn, M., Coe, H., and Kreidenweis, S. M.: Impacts of nonrefractory material on light absorption by aerosols emitted from biomass burning, J. Geophys. Res., 119, 12272-12286, https://doi.org/10.1002/2014JD021750, 2014.
Metcalf, A. R., Loza, C. L., Coggon, M. M., Craven, J. S., Jonsson, H. H., Flagan, R. C., and Seinfeld, J. H.: Secondary Organic Aerosol Coating Formation and Evaporation: Chamber Studies Using Black Carbon Seed Aerosol and the SingleParticle Soot Photometer, Aerosol. Sci. Tech., 47, 326-347, https://doi.org/10.1080/02786826.2012.750712, 2013.

Millet, D. B., Donahue, N. M., Pandis, S. N., Polidori, A., Stanier, C. O., Turpin, B. J., and Goldstein, A. H.: Atmospheric volatile organic compound measurements during the Pittsburgh Air Quality Study: Results, interpretation, and quantification of primary and secondary contributions, J. Geophys. Res., 110, D07S07, https://doi.org/10.1029/2004jd004601, 2005.

Ming, J., Cachier, H., Xiao, C., Qin, D., Kang, S., Hou, S., and $\mathrm{Xu}, \mathrm{J}$.: Black carbon record based on a shallow Himalayan ice core and its climatic implications, Atmos. Chem. Phys., 8, 13431352, https://doi.org/10.5194/acp-8-1343-2008, 2008.

Moffet, R. C. and Prather, K. A.: In-situ measurements of the mixing state and optical properties of soot with implications for radiative forcing estimates, P. Natl. Acad. Sci. USA, 106, 1187211877, https://doi.org/10.1073/pnas.0900040106, 2009.

Mohr, C., Huffman, J. A., Cubison, M. J., Aiken, A. C., Docherty, K. S., Kimmel, J. R., Ulbrich, I. M., Hannigan, M., and Jimenez, J. L.: Characterization of Primary Organic Aerosol Emissions from Meat Cooking, Trash Burning, and Motor Vehicles with High-Resolution Aerosol Mass Spectrometry and Comparison with Ambient and Chamber Observations, Environ. Sci. Technol., 43, 2443-2449, https://doi.org/10.1021/es8011518, 2009.

Moise, T., Flores, J. M., and Rudich, Y.: Optical Properties of Secondary Organic Aerosols and Their Changes by Chemical Processes, Chem. Rev., 115, 4400-4439, https://doi.org/10.1021/cr5005259, 2015.

Moosmüller, H., Chakrabarty, R. K., Ehlers, K. M., and Arnott, W. P.: Absorption Angstrom coefficient, brown carbon, and aerosols: basic concepts, bulk matter, and spherical particles, Atmos. Chem. Phys., 11, 1217-1225, https://doi.org/10.5194/acp11-1217-2011, 2011.

Nenes, A., Conant, W. C., and Seinfeld, J. H.: Black carbon radiative heating effects on cloud microphysics and implications for the aerosol indirect effect 2. Cloud microphysics, J. Geophys. Res., 107, AAC 24-21-AAC 24-11, https://doi.org/10.1029/2002jd002101, 2002.

Nordmann, S., Cheng, Y. F., Carmichael, G. R., Yu, M., Denier van der Gon, H. A. C., Zhang, Q., Saide, P. E., Pöschl, U., Su, H., Birmili, W., and Wiedensohler, A.: Atmospheric black carbon and warming effects influenced by the source and absorption enhancement in central Europe, Atmos. Chem. Phys., 14, 1268312699, https://doi.org/10.5194/acp-14-12683-2014, 2014.

Pathak, R., Donahue, N. M., and Pandis, S. N.: Ozonolysis of â-Pinene: Temperature Dependence of Secondary Organic Aerosol Mass Fraction, Environ. Sci. Technol., 42, 5081-5086, https://doi.org/10.1021/es070721z, 2008.

Pei, X., Hallquist, M., Eriksson, A. C., Pagels, J., Donahue, N. M., Mentel, T., Svenningsson, B., Brune, W., and Pathak, R. K.: Morphological transformation of soot: investigation of microphysical processes during the condensation of sulfuric acid and limonene ozonolysis product vapors, Atmos. Chem. Phys., 18, 9845-9860, https://doi.org/10.5194/acp-18-9845-2018, 2018.

Peng, J., Hu, M., Guo, S., Du, Z., Zheng, J., Shang, D., Levy Zamora, M., Zeng, L., Shao, M., Wu, Y.-S., Zheng, 
J., Wang, Y., Glen, C. R., Collins, D. R., Molina, M. J., and Zhang, R.: Markedly enhanced absorption and direct radiative forcing of black carbon under polluted urban environments, P. Natl. Acad. Sci. USA, 113, 4266-4271, https://doi.org/10.1073/pnas.1602310113, 2016.

Peng, J., Hu, M., Guo, S., Du, Z., Shang, D., Zheng, J., Zheng, J., Zeng, L., Shao, M., Wu, Y., Collins, D., and Zhang, R.: Ageing and hygroscopicity variation of black carbon particles in Beijing measured by a quasi-atmospheric aerosol evolution study (QUALITY) chamber, Atmos. Chem. Phys., 17, 10333-10348, https://doi.org/10.5194/acp-17-10333-2017, 2017.

Pokhrel, R. P., Wagner, N. L., Langridge, J. M., Lack, D. A., Jayarathne, T., Stone, E. A., Stockwell, C. E., Yokelson, R. J., and Murphy, S. M.: Parameterization of single-scattering albedo (SSA) and absorption Ångström exponent (AAE) with EC/OC for aerosol emissions from biomass burning, Atmos. Chem. Phys., 16, 9549-9561, https://doi.org/10.5194/acp-169549-2016, 2016.

Qin, Y. M., Tan, H. B., Li, Y. J., Li, Z. J., Schurman, M. I., Liu, L., Wu, C., and Chan, C. K.: Chemical characteristics of brown carbon in atmospheric particles at a suburban site near Guangzhou, China, Atmos. Chem. Phys., 18, 16409-16418, https://doi.org/10.5194/acp-18-16409-2018, 2018.

Radney, J. G., You, R., Zachariah, M. R., and Zangmeister, C. D.: Direct In Situ Mass Specific Absorption Spectra of Biomass Burning Particles Generated from Smoldering Hard and Softwoods, Environ. Sci. Technol., 51, 5622-5629, https://doi.org/10.1021/acs.est.7b00810, 2017.

Ray, D., Singh, S., Ghosh, S. K., and Raha, S.: Dynamic response of light absorption by $\mathrm{PM}_{2.5}$ bound water-soluble organic carbon to heterogeneous oxidation, Aerosol. Sci. Tech., 53, 1-11, https://doi.org/10.1080/02786826.2019.1661350, 2019.

Reid, J. S., Eck, T. F., Christopher, S. A., Koppmann, R., Dubovik, O., Eleuterio, D. P., Holben, B. N., Reid, E. A., and Zhang, J.: A review of biomass burning emissions part III: intensive optical properties of biomass burning particles, Atmos. Chem. Phys., 5, 827-849, https://doi.org/10.5194/acp-5-827-2005, 2005.

Roden, C. A., Bond, T. C., Conway, S., and Pinel, A. B. O.: Emission factors and real-time optical properties of particles emitted from traditional wood burning cookstoves, Environ. Sci. Technol., 40, 6750-6757, https://doi.org/10.1021/es052080i, 2006.

Romonosky, D. E., Gomez, S. L., Lam, J., Carrico, C. M., Aiken, A. C., Chylek, P., and Dubey, M. K.: Optical Properties of Laboratory and Ambient Biomass Burning Aerosols: Elucidating Black, Brown, and Organic Carbon Components and Mixing Regimes, J. Geophys. Res., 124, 5088-5105, https://doi.org/10.1029/2018jd029892, 2019.

Ruppel, M. M., Isaksson, E., Ström, J., Beaudon, E., Svensson, J., Pedersen, C. A., and Korhola, A.: Increase in elemental carbon values between 1970 and 2004 observed in a 300year ice core from Holtedahlfonna (Svalbard), Atmos. Chem. Phys., 14, 11447-11460, https://doi.org/10.5194/acp-14-114472014, 2014.

Saathoff, H., Naumann, K. H., Schnaiter, M., Schöck, W., Möhler, O., Schurath, U., Weingartner, E., Gysel, M., and Baltensperger, U.: Coating of soot and $\left(\mathrm{NH}_{4}\right)_{2} \mathrm{SO}_{4}$ particles by ozonolysis products of á-pinene, J. Aerosol. Sci., 34, 1297-1321, https://doi.org/10.1016/S0021-8502(03)00364-1, 2003.
Saliba, G., Subramanian, R., Saleh, R., Ahern, A. T., Lipsky, E. M., Tasoglou, A., Sullivan, R. C., Bhandari, J., Mazzoleni, C., and Robinson, A. L.: Optical properties of black carbon in cookstove emissions coated with secondary organic aerosols: Measurements and modeling, Aerosol. Sci. Tech., 50, 1264-1276, https://doi.org/10.1080/02786826.2016.1225947, 2016.

Santos, G. T. A. D., Santos, P. S. M., and Duarte, A. C.: Vanillic and syringic acids from biomass burning: Behaviour during Fenton-like oxidation in atmospheric aqueous phase and in the absence of light, J. Hazard. Mater., 313, 201-208, https://doi.org/10.1016/j.jhazmat.2016.04.006, 2016.

Santos, P. S. M. and Duarte, A. C.: Fenton-like oxidation of small aromatic acids from biomass burning in water and in the absence of light: Implications for atmospheric chemistry, Chemosphere, 119, 786-793, https://doi.org/10.1016/j.chemosphere.2014.08.024, 2015.

Santos, P. S. M., Domingues, M. R. M., and Duarte, A. C.: Fentonlike oxidation of small aromatic acids from biomass burning in atmospheric water and in the absence of light: Identification of intermediates and reaction pathways, Chemosphere, 154, 599603, https://doi.org/10.1016/j.chemosphere.2016.04.015, 2016.

Schmidl, C., Marr, I. L., Caseiro, A., Kotianová, P., Berner, A., Bauer, H., Kasper-Giebl, A., and Puxbaum, H.: Chemical characterisation of fine particle emissions from wood stove combustion of common woods growing in midEuropean Alpine regions, Atmos. Environ., 42, 126-141, https://doi.org/10.1016/j.atmosenv.2007.09.028, 2008.

Schnaiter, M., Linke, C., Mohler, O., Naumann, K. H., Saathoff, H., Wagner, R., Schurath, U., and Wehner, B.: Absorption amplification of black carbon internally mixed with secondary organic aerosol, J. Geophys. Res., 110, D19204, https://doi.org/10.1029/2005JD006046, 2005.

Schwarz, J., Gao, R., Spackman, J., Watts, L., Thomson, D., Fahey, D., Ryerson, T., Peischl, J., Holloway, J., and Trainer, M.: Measurement of the mixing state, mass, and optical size of individual black carbon particles in urban and biomass burning emissions, Geophys. Res. Lett., 35, L13810, https://doi.org/10.1029/2008GL033968, 2008a.

Schwarz, J. P., Spackman, J. R., Fahey, D. W., Gao, R. S., Lohmann, U., Stier, P., Watts, L. A., Thomson, D. S., Lack, D. A., Pfister, L., Mahoney, M. J., Baumgardner, D., Wilson, J. C., and Reeves, J. M.: Coatings and their enhancement of black carbon light absorption in the tropical atmosphere, J. Geophys. Res. 113, D03203, https://doi.org/10.1029/2007JD009042, 2008b.

Shapiro, E. L., Szprengiel, J., Sareen, N., Jen, C. N., Giordano, M. R., and McNeill, V. F.: Light-absorbing secondary organic material formed by glyoxal in aqueous aerosol mimics, Atmos. Chem. Phys., 9, 2289-2300, https://doi.org/10.5194/acp-9-2289-2009, 2009.

Shen, G., Chen, Y., Wei, S., Fu, X., Zhu, Y., and Tao, S.: Mass absorption efficiency of elemental carbon for source samples from residential biomass and coal combustions, Atmos. Environ., 79, 79-84, https://doi.org/10.1016/j.atmosenv.2013.05.082, 2013.

Shiraiwa, M., Kondo, Y., Iwamoto, T., and Kita, K.: Amplification of Light Absorption of Black Carbon by Organic Coating, Aerosol. Sci. Tech., 44, 46-54, https://doi.org/10.1080/02786820903357686, 2010.

Simoneit, B. R. T.: Biomass burning - A review of organic tracers for smoke from incomplete combustion, Appl. Geochem. 
17, 129-162, https://doi.org/10.1016/S0883-2927(01)00061-0, 2002.

Sumlin, B. J., Pandey, A., Walker, M. J., Pattison, R. S., Williams, B. J., and Chakrabarty, R. K.: Atmospheric Photooxidation Diminishes Light Absorption by Primary Brown Carbon Aerosol from Biomass Burning, Environ. Sci. Tech. Let., 4, 540-545, https://doi.org/10.1021/acs.estlett.7b00393, 2017.

Tang, M., Alexander, J. M., Kwon, D., Estillore, A. D., Laskina, O., Young, M. A., Kleiber, P. D., and Grassian, V. H.: Optical and Physicochemical Properties of Brown Carbon Aerosol: Light Scattering, FTIR Extinction Spectroscopy, and Hygroscopic Growth, J. Phys. Chem. A, 120, 4155-4166, https://doi.org/10.1021/acs.jpca.6b03425, 2016.

Thamban, N. M., Tripathi, S. N., Moosakutty, S. P., Kuntamukkala, P., and Kanawade, V. P.: Internally mixed black carbon in the Indo-Gangetic Plain and its effect on absorption enhancement, Atmos. Res., 197, 211-223, https://doi.org/10.1016/j.atmosres.2017.07.007, 2017.

Tian, J., Wang, Q., Ni, H., Wang, M., Zhou, Y., Han, Y., Shen, Z., Pongpiachan, S., Zhang, N., Zhao, Z., Zhang, Q., Zhang, Y., Long, X., and Cao, J.: Emission Characteristics of Primary Brown Carbon Absorption From Biomass and Coal Burning: Development of an Optical Emission Inventory for China, J. Geophys. Res., 124, 1879-1893, https://doi.org/10.1029/2018JD029352, 2019.

Tian, M., Liu, Y., Yang, F., Zhang, L., Peng, C., Chen, Y., Shi, G., Wang, H., Luo, B., Jiang, C., Li, B., Takeda, N., and Koizumi, K.: Increasing importance of nitrate formation for heavy aerosol pollution in two megacities in Sichuan Basin, southwest China, Environ. Pollut., 250, 898-905, https://doi.org/10.1016/j.envpol.2019.04.098, 2019.

Turpin, B. J. and Huntzicker, J. J.: Identification of secondary organic aerosol episodes and quantitation of primary and secondary organic aerosol concentrations during SCAQS, Atmos. Environ., 29, 3527-3544, https://doi.org/10.1016/1352-2310(94)00276-Q, 1995.

Ueda, S., Nakayama, T., Taketani, F., Adachi, K., Matsuki, A., Iwamoto, Y., Sadanaga, Y., and Matsumi, Y.: Light absorption and morphological properties of soot-containing aerosols observed at an East Asian outflow site, Noto Peninsula, Japan, Atmos. Chem. Phys., 16, 2525-2541, https://doi.org/10.5194/acp16-2525-2016, 2016.

Virkkula, A., Makela, T., Hillamo, R., Yli-Tuomi, T., Hirsikko, A., Hameri, K., and Koponen, I. K.: A simple procedure for correcting loading effects of aethalometer data, J. Air Waste Manage., 57, 1214-1222, https://doi.org/10.3155/1047-3289.57.10.1214, 2007.

Wang, J., Zhang, Q., Chen, M., Collier, S., Zhou, S., Ge, X., Xu, J., Shi, J., Xie, C., Hu, J., Ge, S., Sun, Y., and Coe, H.: First Chemical Characterization of Refractory Black Carbon Aerosols and Associated Coatings over the Tibetan Plateau (4730 m a.s.1), Environ. Sci. Technol., 51, 14072-14082, https://doi.org/10.1021/acs.est.7b03973, 2017a.

Wang, J., Zhao, B., Wang, S., Yang, F., Xing, J., Morawska, L., Ding, A., Kulmala, M., Kerminen, V.-M., Kujansuu, J., Wang, Z., Ding, D., Zhang, X., Wang, H., Tian, M., Petäjä, T., Jiang, J., and Hao, J.: Particulate matter pollution over China and the effects of control policies, Sci. Total Environ., 584-585, 426447, https://doi.org/10.1016/j.scitotenv.2017.01.027, 2017b.
Wang, Q., Huang, R., Zhao, Z., Cao, J., Ni, H., Tie, X., Zhu, C., Shen, Z., Wang, M., and Dai, W.: Effects of photochemical oxidation on the mixing state and light absorption of black carbon in the urban atmosphere of China, Environ. Res. Lett., 12, 044012, https://doi.org/10.1088/1748-9326/aa64ea, 2017.

Wang, Q., Cao, J., Han, Y., Tian, J., Zhang, Y., Pongpiachan, S., Zhang, Y., Li, L., Niu, X., Shen, Z., Zhao, Z., Tipmanee, D., Bunsomboonsakul, S., Chen, Y., and Sun, J.: Enhanced light absorption due to the mixing state of black carbon in fresh biomass burning emissions, Atmos. Environ., 180, 184-191, https://doi.org/10.1016/j.atmosenv.2018.02.049, 2018a.

Wang, Q., Cao, J., Han, Y., Tian, J., Zhu, C., Zhang, Y., Zhang, N., Shen, Z., Ni, H., Zhao, S., and Wu, J.: Sources and physicochemical characteristics of black carbon aerosol from the southeastern Tibetan Plateau: internal mixing enhances light absorption, Atmos. Chem. Phys., 18, 4639-4656, https://doi.org/10.5194/acp18-4639-2018, 2018b.

Wang, Q. Y., Huang, R. J., Cao, J. J., Han, Y. M., Wang, G. H., Li, G. H., Wang, Y. C., Dai, W. T., Zhang, R. J., and Zhou, Y. Q.: Mixing State of Black Carbon Aerosol in a Heavily Polluted Urban Area of China: Implications for Light Absorption Enhancement, Aerosol. Sci. Tech., 48, 689-697, https://doi.org/10.1080/02786826.2014.917758, 2014.

Wang, Y., Chen, Y., Wu, Z., Shang, D., Bian, Y., Du, Z., Schmitt, S. H., Su, R., Gkatzelis, G. I., Schlag, P., Hohaus, T., Voliotis, A., Lu, K., Zeng, L., Zhao, C., Alfarra, R., McFiggans, G., Wiedensohler, A., Kiendler-Scharr, A., Zhang, Y., and Hu, M.: Mutual promotion effect between aerosol particle liquid water and nitrate formation lead to severe nitrate-dominated particulate matter pollution and low visibility, Atmos. Chem. Phys. Discuss., https://doi.org/10.5194/acp-2019-716, in review, 2019.

Wang, Y. Q.: MeteoInfo: GIS software for meteorological data visualization and analysis, Meteorol. Appl., 21, 360-368, https://doi.org/10.1002/met.1345, 2014.

Wang, Y. Q.: An Open Source Software Suite for MultiDimensional Meteorological Data Computation and Visualisation, Journal of Open Research Software, 7, 21, https://doi.org/10.5334/jors.267, 2019.

Warren, B., Austin, R. L., and Cocker, D. R.: Temperature dependence of secondary organic aerosol, Atmos. Environ., 43, 35483555, https://doi.org/10.1016/j.atmosenv.2009.04.011, 2009.

Wei, Y., Ma, L., Cao, T., Zhang, Q., Wu, J., Buseck, P. R., and Thompson, J. E.: Light Scattering and Extinction Measurements Combined with Laser-Induced Incandescence for the Real-Time Determination of Soot Mass Absorption Cross Section, Anal. Chem., 85, 9181-9188, https://doi.org/10.1021/ac401901b, 2013.

Weyant, C. L., Shepson, P. B., Subramanian, R., Cambaliza, M. O. L., Heimburger, A., McCabe, D., Baum, E., Stirm, B. H., and Bond, T. C.: Black Carbon Emissions from Associated Natural Gas Flaring, Environ. Sci. Technol., 50, 2075-2081, https://doi.org/10.1021/acs.est.5b04712, 2016.

Wilcox, E. M., Thomas, R. M., Praveen, P. S., Pistone, K., Bender, F. A.-M., and Ramanathan, V.: Black carbon solar absorption suppresses turbulence in the atmospheric boundary layer, P. Natl. Acad. Sci., 113, 11794-11799, https://doi.org/10.1073/pnas.1525746113, 2016.

Williams, M. A., Kumar, T. V. L., and Rao, D. N.: Characterizing black carbon aerosols in relation to atmospheric 
boundary layer height during wet removal processes over a semi urban location, J. Atmos. Sol.-Terr. Phy., 182, 165-176, https://doi.org/10.1016/j.jastp.2018.11.018, 2019.

Wong, J. P. S., Tsagkaraki, M., Tsiodra, I., Mihalopoulos, N., Violaki, K., Kanakidou, M., Sciare, J., Nenes, A., and Weber, R. J.: Atmospheric evolution of molecular-weight-separated brown carbon from biomass burning, Atmos. Chem. Phys., 19, 73197334, https://doi.org/10.5194/acp-19-7319-2019, 2019.

Wu, C.: Histbox, Zenodo, https://doi.org/10.5281/zenodo.832405, 2020a.

Wu, C.: MRS, Zenodo, https://doi.org/10.5281/zenodo.832395, 2020 b.

Wu, C.: Scatter Plot, Zenodo, https://doi.org/10.5281/zenodo.832416, 2020c.

Wu, C. and Yu, J. Z.: Determination of primary combustion source organic carbon-to-elemental carbon (OC/EC) ratio using ambient OC and EC measurements: secondary OC-EC correlation minimization method, Atmos. Chem. Phys., 16, 5453-5465, https://doi.org/10.5194/acp-16-5453-2016, 2016.

$\mathrm{Wu}, \mathrm{C}$. and $\mathrm{Yu}$, J. Z.: Evaluation of linear regression techniques for atmospheric applications: the importance of appropriate weighting, Atmos. Meas. Tech., 11, 1233-1250, https://doi.org/10.5194/amt-11-1233-2018, 2018.

Wu, C., Ng, W. M., Huang, J., Wu, D., and Yu, J. Z.: Determination of Elemental and Organic Carbon in $\mathrm{PM}_{2.5}$ in the Pearl River Delta Region: Inter-Instrument (Sunset vs. DRI Model 2001 Thermal/Optical Carbon Analyzer) and Inter-Protocol Comparisons (IMPROVE vs. ACE-Asia Protocol), Aerosol. Sci. Tech., 46, 610-621, https://doi.org/10.1080/02786826.2011.649313, 2012.

Wu, C., Wu, D., and Yu, J. Z.: Quantifying black carbon light absorption enhancement with a novel statistical approach, Atmos. Chem. Phys., 18, 289-309, https://doi.org/10.5194/acp-18-2892018, 2018.

Wu, C., Wu, D., and Yu, J. Z.: Estimation and Uncertainty Analysis of Secondary Organic Carbon Using One-Year of Hourly Organic and Elemental Carbon Data, J. Geophys. Res., 124, 2774 2795, https://doi.org/10.1029/2018JD029290, 2019.

Xia, Y., Zhao, Y., and Nielsen, C. P.: Benefits of China's efforts in gaseous pollutant control indicated by the bottom-up emissions and satellite observations 2000-2014, Atmos. Environ., 136, 4353, https://doi.org/10.1016/j.atmosenv.2016.04.013, 2016.

Xie, C., Xu, W., Wang, J., Liu, D., Ge, X., Zhang, Q., Wang, Q., Du, W., Zhao, J., Zhou, W., Li, J., Fu, P., Wang, Z., Worsnop, D., and Sun, Y.: Light absorption enhancement of black carbon in urban Beijing in summer, Atmos. Environ., 213, 499-504, https://doi.org/10.1016/j.atmosenv.2019.06.041, 2019.

Xie, S., Zhang, Y., Qi, L., and Tang, X.: Spatial distribution of traffic-related pollutant concentrations in street canyons, Atmos. Environ., 37, 3213-3224, https://doi.org/10.1016/S13522310(03)00321-2, 2003.

Xu, J., Cui, T., Fowler, B., Fankhauser, A., Yang, K., Surratt, J. D., and McNeill, V. F.: Aerosol Brown Carbon from Dark Reactions of Syringol in Aqueous Aerosol Mimics, ACS Earth and Space Chemistry, 2, 608-617, https://doi.org/10.1021/acsearthspacechem.8b00010, 2018a.

Xu, J., Wang, Q., Deng, C., McNeill, V. F., Fankhauser, A., Wang, F., Zheng, X., Shen, J., Huang, K., and Zhuang, G.: Insights into the characteristics and sources of primary and secondary organic carbon: High time resolution observation in urban Shanghai, Environ. Pollut., 233, 1177-1187, https://doi.org/10.1016/j.envpol.2017.10.003, 2018b.

Xu, Q., Wang, S., Jiang, J., Bhattarai, N., Li, X., Chang, X., Qiu, X., Zheng, M., Hua, Y., and Hao, J.: Nitrate dominates the chemical composition of $\mathrm{PM}_{2.5}$ during haze event in Beijing, China, Sci. Total Environ., 689, 1293-1303, https://doi.org/10.1016/j.scitotenv.2019.06.294, 2019.

Xu, X., Zhao, W., Zhang, Q., Wang, S., Fang, B., Chen, W., Venables, D. S., Wang, X., Pu, W., Wang, X., Gao, X., and Zhang, W.: Optical properties of atmospheric fine particles near Beijing during the HOPE-J3A campaign, Atmos. Chem. Phys., 16, 6421-6439, https://doi.org/10.5194/acp-16-6421-2016, 2016.

Xu, X., Zhao, W., Qian, X., Wang, S., Fang, B., Zhang, Q., Zhang, W., Venables, D. S., Chen, W., Huang, Y., Deng, X., Wu, B., Lin, X., Zhao, S., and Tong, Y.: The influence of photochemical aging on light absorption of atmospheric black carbon and aerosol single-scattering albedo, Atmos. Chem. Phys., 18, 16829-16844, https://doi.org/10.5194/acp-18-16829-2018, 2018.

Xue, H. X., Khalizov, A. F., Wang, L., Zheng, J., and Zhang, R. Y.: Effects of dicarboxylic acid coating on the optical properties of soot, Phys. Chem. Chem. Phys., 11, 7869-7875, https://doi.org/10.1039/b904129j, 2009.

Xue, J., Yuan, Z., Lau, A. K. H., and Yu, J. Z.: Insights into factors affecting nitrate in $\mathrm{PM}_{2.5}$ in a polluted high $\mathrm{NO}_{x}$ environment through hourly observations and size distribution measurements, J. Geophys. Res., 119, 4888-4902, https://doi.org/10.1002/2013JD021108, 2014.

Yao, Z., Zhang, Y., Shen, X., Wang, X., Wu, Y., and He, K.: Impacts of temporary traffic control measures on vehicular emissions during the Asian Games in Guangzhou, China, J. Air Waste Manage., 63, 11-19, https://doi.org/10.1080/10962247.2012.724041, 2013.

Ye, Z., Qu, Z., Ma, S., Luo, S., Chen, Y., Chen, H., Chen, Y., Zhao, Z., Chen, M., and Ge, X.: A comprehensive investigation of aqueous-phase photochemical oxidation of 4-ethylphenol, Sci. Total Environ., 685, 976-985, https://doi.org/10.1016/j.scitotenv.2019.06.276, 2019.

Ying, Q., Feng, M., Song, D., Wu, L., Hu, J., Zhang, H., Kleeman, M. J., and Li, X.: Improve regional distribution and source apportionment of $\mathrm{PM}_{2.5}$ trace elements in China using inventoryobservation constrained emission factors, Sci. Total Environ., 624, 355-365, https://doi.org/10.1016/j.scitotenv.2017.12.138, 2018.

You, R., Radney, J. G., Zachariah, M. R., and Zangmeister, C. D.: Measured Wavelength-Dependent Absorption Enhancement of Internally Mixed Black Carbon with Absorbing and Nonabsorbing Materials, Environ. Sci. Technol., 50, 7982-7990, https://doi.org/10.1021/acs.est.6b01473, 2016.

Zhang, G., Bi, X., Li, L., Chan, L. Y., Li, M., Wang, X., Sheng, G., Fu, J., and Zhou, Z.: Mixing state of individual submicron carbon-containing particles during spring and fall seasons in urban Guangzhou, China: a case study, Atmos. Chem. Phys., 13, 4723-4735, https://doi.org/10.5194/acp-13-4723-2013, 2013.

Zhang, G., Han, B., Bi, X., Dai, S., Huang, W., Chen, D., Wang, X., Sheng, G., Fu, J., and Zhou, Z.: Characteristics of individual particles in the atmosphere of Guangzhou by single particle mass spectrometry, Atmos. Res., 153, 286-295, https://doi.org/10.1016/j.atmosres.2014.08.016, 2015. 
Zhang, G. H., Bi, X. H., He, J. J., Chen, D. H., Chan, L. Y., Xie, G. W., Wang, X. M., Sheng, G. Y., Fu, J. M., and Zhou, Z.: Variation of secondary coatings associated with elemental carbon by single particle analysis, Atmos. Environ., 92, 162-170, https://doi.org/10.1016/j.atmosenv.2014.04.018, 2014.

Zhang, R. Y., Khalizov, A. F., Pagels, J., Zhang, D., Xue, H. X., and McMurry, P. H.: Variability in morphology, hygroscopicity, and optical properties of soot aerosols during atmospheric processing, P. Natl. Acad. Sci. USA, 105, 10291-10296, https://doi.org/10.1073/pnas.0804860105, 2008.

Zhang, X., Mao, M., Yin, Y., and Wang, B.: Absorption enhancement of aged black carbon aerosols affected by their microphysics: A numerical investigation, J. Quant. Spectrosc. Ra., 202, 90-97, https://doi.org/10.1016/j.jqsrt.2017.07.025, 2017.

Zhang, Y., Favez, O., Canonaco, F., Liu, D., Močnik, G., Amodeo, T., Sciare, J., Prévôt, A. S. H., Gros, V., and Albinet, A.: Evidence of major secondary organic aerosol contribution to lensing effect black carbon absorption enhancement, Climate and Atmospheric Science, 1, 47, https://doi.org/10.1038/s41612-0180056-2, 2018a.
Zhang, Y., Zhang, Q., Cheng, Y., Su, H., Li, H., Li, M., Zhang, X., Ding, A., and He, K.: Amplification of light absorption of black carbon associated with air pollution, Atmos. Chem. Phys., 18, 9879-9896, https://doi.org/10.5194/acp-18-9879-2018, 2018 b.

Zhong, M. and Jang, M.: Light absorption coefficient measurement of SOA using a UV-Visible spectrometer connected with an integrating sphere, Atmos. Environ., 45, 4263-4271, https://doi.org/10.1016/j.atmosenv.2011.04.082, 2011.

Zhong, M. and Jang, M.: Dynamic light absorption of biomass-burning organic carbon photochemically aged under natural sunlight, Atmos. Chem. Phys., 14, 1517-1525, https://doi.org/10.5194/acp-14-1517-2014, 2014.

Zhou, Y., Huang, X. H. H., Griffith, S. M., Li, M., Li, L., Zhou, Z., Wu, C., Meng, J., Chan, C. K., Louie, P. K. K., and Yu, J. Z.: A field measurement based scaling approach for quantification of major ions, organic carbon, and elemental carbon using a single particle aerosol mass spectrometer, Atmos. Environ., 143, 300 312, https://doi.org/10.1016/j.atmosenv.2016.08.054, 2016. 